Processing Technology

Elsevier Editorial System(tm) for Fuel

Manuscript Draft

Manuscript Number: FUPROC-D-15-00926R2

Title: Computational modelling of the condensation of fast pyrolysis vapours in a quenching column. Part B: Phase change dynamics and column size effects.

Article Type: Research Article

Keywords: Condensation; Liquid collection system; Quenching column; Species transport; Fast pyrolysis; Phase change

Corresponding Author: Dr. Konstantinos Papadikis, Ph.D.

Corresponding Author's Institution: Xi an Jiaotong Liverpool University

First Author: V. S. Kiran Kumar Palla

Order of Authors: V. S. Kiran Kumar Palla; Konstantinos Papadikis, Ph.D.; Sai Gu 


\section{Response to Reviewers:}

We would like to thank the reviewer for his valuable comments. The text modifications from the first revision are shown in blue colour whilst the modifications from the second revision are shown in green colour. Please find our responses below:

\section{Reviewer \#1:}

This paper is on fractional condensation of pyrolysis vapors. A useful topic and useful work for the pyrolysis community. Some comments on the paper are listed below that might help to improve the paper.

- There are quite some graphs. Are they all needed? Please check.

Our response: The mass source per segment graph has been removed as it is closely related to the graph of the enthalpy of condensation. Hence, Figure 11 was removed and Figure 12 renamed to Figure 11. The results section was updated from line 418-420.

- This paper promises on the condensation of fast pyrolysis vapors, however;

- The paper only takes into account the light fraction of pyrolysis oil. The oil contains many aerosols (lignin derived oligomers and sugar derived oligomers).

I don't think that a mono-phenolic (guaiacol, etc.) describes this fraction because its boiling point is around $200{ }^{\circ} \mathrm{C}$.

At high temperature condenser operation (e.g. $80^{\circ} \mathrm{C}$ ) and high gas flow rate (for example in fluidized beds) these mono-phenols have quite some vapor pressure whereas lignin derived oligomers are basically solids. They are only liquid because they dissolve in the other pyrolysis oil compounds.

Please scale down the expectation in the abstract/introduction or include a fraction of the oil (lumped) representing compounds with no vapor pressure.

Our response: In this work, Phenol, Guaiacol and Coniferyl alcohol were chosen as the primary compounds to represent the products of the thermal decomposition of lignin. We certainly agree with the reviewer's comments that Guaiacol and Coniferyl alcohol cannot be regarded as a complete representation of the lignin derived oligomers. The abstract and the description of the condensation model (lines 148-150) have been further revised based on the reviewer's suggestions to clarify this fact. The abstract has also been shortened to comply with the guide for authors.

However, we would like to point out that our modelling approach does not refer to a specific biomass composition but rather to an average composition reported in the literature where the pyrolytic lignin was chosen to be represented by the previously mentioned compounds. The addition of even a single extra compound will inevitably alter the initial distribution of all the compounds in the affected family (please see lines 133-140, 151-156 on how the discrete representation works). Hence, if the scope of the work is to study the effect of lignin derived oligomers the model can be tuned/calibrated in such a way that those are taken into account. Our primary scope is to predict the condensation of a discrete representation of the condensable pyrolysis compounds as those have been previously reported in the literature in 
the works of Brett et al. which is based on the work of Hallett and Clark. The lines 140-142 were also added in the paper as a suggestion for classifying the pyrolysis vapours.

- Could you include experimental data to validate the model.

There should be condenser conditions and compounds behavior available in literature to at least give it a check?

Our response: Lines 49-50, 56-57, 74-76 and 85-86 were added to enhance the literature study on the existing experiments.

The results from the PhD Thesis of Abba Sani Kalgo from Aston University which were obtained from the direct contact condenser in co-current flow further reinforced the predictions of this model. Moreover, the experiments conducted by Tumbalam Gooty et al. also showed similar trends in terms of condensation behaviour even though the condensers used are of the indirect contact type. The prediction of our model also agrees with Westerhoff et al.'s overall predictions.

The reference list has been updated to support the text inclusions in the Introduction and Results sections. The Results section has been updated with lines 395-399, 416-417, 435-436 to add more validity to the condensation CFD model. 


\section{Highlights}

- The fractional condensation of pyrolysis vapours in a quenching column is simulated

- The effect of the number of disc-donut stages in the column is investigated

- A discrete representation of the pyrolysis vapours is utilized

- High volatility compounds are partially condensed

- Column pressure build up aids the conversion of the highly volatile compounds 


\section{Computational modelling of the condensation of fast pyrolysis vapours in a 2 quenching column. Part B: Phase change dynamics and column size effects.}

\author{
V. S. Kiran Kumar Palla ${ }^{1,2}$, K. Papadikis ${ }^{1 *}$, S. Gu. ${ }^{3 *}$
}

${ }^{1}$ Civil Engineering Department, Xi'an Jiaotong-Liverpool University, Suzhou, China.

${ }^{2}$ School of Engineering, University of Liverpool, Liverpool, U.K.

${ }^{3}$ Chemical and Process Engineering, University of Surrey, Guildford, Surrey GU2 7XH, U.K. *Corresponding author

E-mail address: konstantinos.papadikis@xjtlu.edu.cn

E-mail address: sai.gu@surrey.ac.uk

\section{Abstract}

The aim of the present work is to provide detailed information on the phase change dynamics of a discrete representation of the pyrolysis vapours in a direct contact heat exchanger (disc and donut quenching column). Eleven compounds were chosen to represent the most common chemical groups found in bio-oil (i.e acids, aldehydes/ketones, pyrolytic lignin and water). The pyrolytic lignin group is represented through mono-phenolic compounds (i.e. phenol, coniferyl alcohol, guaiacol) whereas the effect of sugar and lignin derived oligomers is neglected. The work aims to identify how different numbers of disc and donut pairs (stages) 3,5 and 9, affect the condensation performance of the column. The saturation vapour pressures of the individual compounds were calculated based on corresponding states correlations. It is shown that heavy compounds, such as guaiacol, phenol and coniferyl alcohol condense rapidly even with a low number of stages, whereas an increased number of stages is needed to completely capture the heavier acidic (butyric acid) fractions. In all cases, the majority of the acidic fraction (acetic acid and propionic acid) and water were only partially condensed, whereas formic acid and the aldehyde fraction (propanal and pentanal) were not condensed at any stage of the process.

Keywords: Condensation, Liquid collection system, Quenching column, Species transport, Fast pyrolysis, Phase change.

\section{Introduction}

The demand for fossil fuels has been increased over past few decades due to the rapid growth in terms of global industrialization and development. Moreover, the depletion of fossil fuel reserves coupled with the increasing energy consumption and greenhouse gas emissions poses a new set of challenges. These factors put thrust on the utilisation of renewable energy resources, such as biomass, solar and wind energy. In addition, many countries pledged to reduce the greenhouse gases further intensified the need for renewable energy sources [1].

The use of biomass as a source for energy is one of the alternatives that can contribute to decreasing the share of fossil fuels [2]. Moreover, this will also lead to the reduction of greenhouse gas emissions [3]. When compared with other renewable energy sources, biomass stands as the only source for solid, 
liquid and gaseous fuels. Biomass fast pyrolysis presents certain advantages among all the conversion techniques available for the generation of liquid fuels [4]. This process can provide a liquid fuel that has the potential fuel in any static heating or electricity generation application $[5,6]$.

Fast pyrolysis vapours require to be rapidly condensed for optimum liquid bio-oil yields. The primary requirement for higher liquid bio-oil yields is the rapid condensation of the condensable pyrolysis vapours [8-11]. Hence, high heat transfer rates, carefully controlled temperatures, the residence time of pyrolysis vapours in the reactor are the most significant factors that affect the process. The presence of non-condensable gases in the system poses significant heat and mass transfer resistance as well as low partial pressures that significantly limit the efficient collection of the liquid product. In the case of the conventional heat exchangers, an inherent problem of preferential deposit accumulation of lignin-derived components, which eventually leads to liquid fractionation, is also present [7]. These depositions typically cause blockages of the pipelines and consequently the heat exchanger itself. Moreover, due to the improved thermal performance of direct contact condensers, up to $60 \%$ less cooling medium is often required than that needed in indirect contact condensers [12]. Several types of direct contact condensers are deployed in fast pyrolysis liquid collection systems like spray columns and quenching columns. These direct contact heat exchangers, significantly minimise the previously stated limitations and provide greater contact area between the coolant and the vapours, which in turn aids the rapid cooling of the latter as well as the capturing of the condensed aerosols.

Recently, the sequential condensation of the pyrolysis vapours is gaining significant popularity [1315]. The majority of the experimentalists [15-21] deployed series of indirect condensers to achieve sequential condensation while few others [22-24] used direct contact condensers. The advantage of sequential condensation is that different fractions of bio-oil with different compositions can be collected so that the partial upgrading process can be achieved within the pyrolysis process. This will also contribute to the overall thermal efficiency of the plant $[25,26]$. For this reason, it is essential to understand the physical behaviour of flows within the liquid collection system so that the efficient column designs can be developed.

According to Bridgwater [27], one of the most essential features of fast pyrolysis for the production of liquid fuels is the low vapour residence time. The vapour residence time refers to the time taken by the vapour from its generation in the reactor to the condensation in the liquid collection system. The optimum vapour residence time is typically 2 seconds, which minimises the undesirable secondary reactions that take place in the vapour phase. Secondary cracking tends to increase the percentage of non-condensable gases in the expense of the final liquid bio-oil $[28,29]$. This introduces a significant challenge in the design of efficiently operating quenching columns using empirical relations, which is restricted by the high complexity of the process. The gas-liquid interactions in terms of momentum, heat and mass transport, result in complex flow regimes that are difficult to be predicted by experimentation alone. The thermodynamic condensation model developed by Westerhof et al. [13], 
based on the well-known Rachford-Rice formulation [30], provided an insight on how the water yield can be controlled during the condensation of pyrolysis vapours. In the works of Tumbalam Gooty et al. [31, 32], the results of the models developed in HYSYS tool were utilised as a guide to standardise the practical performance of the fractional condensation series. However, these models can only provide the overall balances and lacks the spatiotemporal details of the parameters within the condensing unit which are necessary to develop efficient designs. Under these considerations, the employment of computational methods to provide an insight on the physical phenomena present in the process (i.e. hydrodynamics, heat transfer and phase change phenomena) becomes increasingly necessary.

Various modelling studies have been undertaken in the modelling of the hydrodynamics of sieve tray columns [33-36]. So far, most of the modelling studies performed in the field of pyrolysis technologies are either focused on particle dynamics [37] or chemical conversion modelling [38] within the fluidised bed reactors. A comprehensive review on the mathematical modelling on pyrolysis reactors has been recently presented in the works of Sharma et al. [39]. Some researchers conducted computational fluid dynamics (CFD) analysis on reactor hydrodynamics and its thermochemical performance with a focus on reducing the residence time of vapours and achieving better separation efficiency $[39,41]$. However, only few research studies have been conducted in the numerical modelling of the condensation of pyrolysis vapours [42]. In this study, the condensation of the mixture of pyrolysis vapours, in the presence of non-condensable gases, is simulated in an indirect contact heat exchanger. The vapours are treated as ideal gases, while the vapour mixture is treated as a unique phase without distinct chemical species. In a later work [43], the assumptions imposing restrictions on selective condensation of different species was improved by treating the vapour phase as a mixture of distinct species. However, the authors have not identified a single study on the numerical modelling and simulation of the condensation of fast pyrolysis vapours within a quenching column.

The aim of the current study is to model the phase change phenomena due to condensation occurring within a quenching column. The gas-liquid interactions are simulated using the immiscible Eulerian Eulerian approach. The assessment of the hydrodynamic performance of the quenching column has been presented in the first part of this study [44]. The chemical thermodynamics governing the condensation process have been incorporated in user-defined subroutines to suit to the flow regimes within the quenching column. The numerical model has been applied for the determination of the optimum number of stages within the quenching column and its effect on the condensation of individual species. The CFD results clearly show the impact of the number of stages, temperature and pressure on the relative saturation of the individual species. Also, the effect of the species volatility on the phase change characteristics is thoroughly analysed and discussed. 


\section{Experimental conditions}

Experimental investigations have been conducted at Aston University, based on the ablative pyrolysis process described by Peacocke et al. [45], for the production of liquid bio-oil. The pyrolysis reactor is designed to operate at a biomass feeding rate of $5 \mathrm{~kg} / \mathrm{hr}$.; however, due to feeder limitations the feeding rate was limited to $3 \mathrm{~kg} / \mathrm{hr}$ [46]. The liquid collection system of the pyrolysis rig comprised of a quenching column coupled with an electrostatic precipitator. The dimensions of the quenching column are based on the maximum intended gas flow rates from the pyrolysis reactor, as well as the flooding factors.

The original (baseline) design of the quenching column and the equipment has been designed for a total gas (i.e. gases plus pyrolysis vapours) flow rate $0.0044 \mathrm{~m}^{3} / \mathrm{s}$ at a temperature of $400^{\circ} \mathrm{C}$. The gaseous composition was estimated based on Toft's [47] empirical relationship. Thus the total gas composition consists of $87 \% \mathrm{~N}_{2}$ by volume, while the remaining $13 \%$ consists of condensable and non-condensable gases.

Octane at $-5^{\circ} \mathrm{C}$ and at a flow rate of $0.025 \mathrm{~kg} / \mathrm{s}$, has been used as the direct contact cooling medium because of its immiscibility with the highly oxygenated hydrocarbons present in the final liquid biooil product. The design specifications of the discs and donuts inside the quenching column are given in Table 1. The experimental findings reported flooding of the quenching column at the design gaseous flow rate of $0.0044 \mathrm{~m}^{3} / \mathrm{s}$. However, the design modifications suggested in the first part of this study eliminated flooding phenomena are also highlighted in Table 1.

\section{Condensation model}

The condensation model used in this paper is an extension to the works of Papadikis et al. [42] and Palla et al. [43]. In the former work, the condensation model was presented using a uniform vapour composition, whereas in the latter one, the model was developed for the indirect contact condensation and modelled using species transport. The current model extended the scope to direct contact condensation with some limitations as described below. The pyrolysis vapour is represented with 11 species. Each individual species is treated as an individual compound which is condensed according to its saturation vapour pressure. The condensation model in this way enables the prediction of the pyrolysis vapour composition accurately at each stage, once the initial vapour composition is known. The inlet pyrolysis vapour composition is highly dependent on the type of feed used during the pyrolysis process and type of reactor and its conditions. These compositions further suggest the type of application for which the bio-oil produced [48]. The selection of the number of chemical species and their corresponding initial volume fractions can be modified depending on the chemical compounds of interest. A more comprehensive classification and grouping can be found in the works of Garcia-Perez et al. [49] where they developed a characterisation approach to determine the bio-oil composition in terms of macro-chemical families. 
The pyrolysis vapours used in this analysis was represented in a discrete form by 11 chemical species typically found in bio-oil. The selected species are listed in Table 2, and have been taken from the bio-oil composition used in the work of Brett et al. [50]. This discrete composition is an equivalent representation of the continuous thermodynamics model used in the study of Hallett and Clark [51], which in turn is based on molecular weight distributions of specific chemical groups found in bio-oils (i.e acids, aldehydes / ketones, pyrolytic lignin and water). It has to be pointed out that in the current work the effect of lignin and sugar derived oligomers have been neglected, whilst the pyrolytic lignin group is simplified to a mono-phenolic representation through phenol, guaiacol and coniferyl alcohol. While making a discrete representation, one has to make sure that the overall average distribution of the affected chemical groups in the continuous description remains unchanged. This inevitably imposes a limitation on the minimum number of discrete chemical compounds in group, which will have to satisfactorily approximate a continuous curve. It has to be noted that the pyrolysis vapours composition does not represent a particular biomass feedstock but rather an average bio-oil representation from several reports found in the literature.

The thermochemical properties of each species (Table 2) have been calculated using existing data available in the literature [52]. The critical properties have been estimated using the group contribution method [53] when they are not readily available in the literature.

\subsection{Vapour-liquid equilibrium (VLE)}

This condensation model utilises the generalized corresponding states method to calculate saturation vapour pressure of each species of the pyrolysis vapour. According to Mejbri and Bellagi's [54] generalized three parameter corresponding states correlation, the natural logarithm of the reduced saturated vapour pressure and acentric factor $\omega^{i}$ are in linear relation as shown in Eq. (1) with an averaged fluctuation about $0.16 \%$

$$
\ln \left(P_{r}^{i}\right)=f_{0}\left(\tau^{i}\right)+\omega^{i} f_{1}\left(\tau^{i}\right),
$$

where $\tau^{i}$ is the inverse of the reduced temperature $T_{r}^{i}$ of the $\mathrm{i}^{\text {th }}$ species and is equal to $1 / T_{r}^{i}$. The functions $f_{0}$ and $f_{1}$ are given by Eqs. (2) and (3)

$$
f_{0}\left(\tau^{i}\right)=\gamma_{1}\left(\tau^{i}-\exp \left(1-\tau^{i}\right)\right)+\gamma_{2}\left(\left(\tau^{i}\right)^{\gamma_{3}}-\exp \left(1-\tau^{i}\right)\right)
$$

and

$$
f_{1}\left(\tau^{i}\right)=\gamma_{4}\left(\tau^{i}-\exp \left(1-\tau^{i}\right)\right)+\gamma_{5}\left(\left(\tau^{i}\right)^{\gamma_{6}}-\exp \left(1-\tau^{i}\right)\right) .
$$

The values of the six universal $\gamma$ coefficients are listed in Table 3 . 
In order to estimate the vapour pressures using Eq. (1), the critical pressures and temperatures are required along with the acentric factor. If the acentric factor is not available, Mejbri and Bellagi [54] recommended estimating it using the boiling temperature $T_{b}^{i}$ as shown in Eq. (4)

$$
\omega^{i}=\left(0.013162987-\ln P_{c}^{i}-f_{0}\left(\tau_{b}^{i}\right)\right) / f_{1}\left(\tau_{b}^{i}\right),
$$

where $\tau_{b}^{i}$ is the ratio of the critical and boiling temperatures i.e. $\tau_{b}^{i}=T_{c}^{i} / T_{b}^{i}$. The critical pressure $P_{c}^{i}$ used in Eq. (4) is expressed in bars.

The condensation rate is governed by the magnitude of the relative saturation value which is the ratio of the vapour fugacity $\left(f_{v}^{i}\right)$ to the saturated vapour fugacity $\left(f_{l}^{i}\right)$. Under the vapour liquid equilibrium (VLE) conditions, the relative saturation will be unity. The vapour fugacity in this case is the partial pressure of the particular species in the system as given in the Eq. (5)

$$
f_{v}^{i}=\phi^{i} P^{i}=\phi^{i} x^{i} P
$$

where $P^{i}$ is the partial pressure of the species ' $i$ ' and $P$ is the total pressure of the mixture. $x^{i}$ is the mole fraction of the $i^{\text {th }}$ species within the vapour mixture.

The saturated vapour fugacity computed from the reduced saturation pressure as shown in Eq. (6)

$$
f_{l}^{i}=\phi_{\text {sat }}^{i} P_{r}^{i} P_{c}^{i}
$$

Here the fugacity coefficients $\phi^{i}$ and $\phi_{\text {sat }}^{i}$ which measures the departure from ideal are assumed as 1 and hence the saturated vapour pressure is considered the same as the saturated vapour fugacity. This is especially true when the system is not under high pressures and is evident from Eq. (7)

$$
\lim _{p \rightarrow 0} \ln \phi^{i}=0 .
$$

\subsection{Thermodynamic properties}

The thermodynamic properties of the vapour mixture are calculated based on the assumption of the ideal mixture behaviour for the pyrolysis vapours. The vapour mixture viscosity is computed based on the Dean and Stiel [55] relation which is a function of the reduced mixture temperature as shown in Eq. (8). The mixture viscosity $\mu_{m}$ in this relation is expressed in micro poise

$$
\mu_{m}=\left\{\begin{array}{ll}
3.4 T_{r m}^{8 / 9} / \xi_{m} & T_{r m} \leq 1.5 \\
16.68\left(0.1338 T_{r m}-0.0932\right)^{5 / 9} / \xi_{m} & T_{r m}>1.5
\end{array},\right.
$$

where $\xi_{m}$ is inverse viscosity and expressed in $\mu P^{-1}$. This can be calculated by using Eq. (9)

$$
\xi_{m}=\left(\frac{T_{c m}}{\left(M_{m}{ }^{3} P_{c m}{ }^{4}\right)}\right)^{1 / 6} .
$$

The reduced mixture temperature $T_{r m}$ is expressed as the ratio between temperature and mixture critical temperature. Here the mixture critical temperatures and mixture molecular weight were calculated by mass fraction weightage basis i.e. $\sum y^{i} T_{c}^{i}, \sum y^{i} M^{i}$ respectively. The mixture critical pressure $P_{c m}$ expressed in atmospheres is calculated using Eq. (10) 


$$
P_{c m}=\frac{R\left(\sum_{i} y^{i} z_{c}^{i}\right)}{\sum_{i} y^{i} V_{c}^{i}} T_{c m} .
$$

The universal gas constant $R$ in Eq. 10 is equal to 82.05746 (atm. cm3/ mol-K).

Due to lack of the group contribution data, in this analysis, the more accurate correlations like Chung et al. [56] are not considered for calculating the thermal conductivity. The famous Eucken correlation offers a simple method to estimate the mixture's thermal conductivity,

$$
k_{m}=\left(1.32+\frac{1.77}{\left(c_{p_{m}} / R-1\right)}\right)\left(\frac{\mu_{m}\left(C_{p_{m}}-R\right)}{M_{m}}\right),
$$

where $k_{m}$ is the thermal conductivity of the vapours, $C_{p_{m}}$ is the heat capacity of the vapours, which is calculated on a mass fraction average, i.e. $\sum w^{i} C_{p}{ }^{i}$. Individual species heat capacities are given in Table 4. These values are obtained from Reid et al. [57] and Stull et al.[58]. The heat of vaporization for each chemical species within the vapour is estimated based on the law of corresponding states. The relationship of the heat of vaporisation with acentric factor, $\omega^{i}$, and the reduced temperature, $T_{r}^{i}$, shown in Eq. (12) is an analytical representation of the Pitzer's [59] correlation

$$
\Delta H_{v}^{i}=\left(7.08\left(1-T_{r}^{i}\right)^{0.354}+10.95 \omega^{i}\left(1-T_{r}^{i}\right)^{0.456}\right) R T_{c}^{i} .
$$

In this work, the bio-oil is treated as a homogeneous compound and hence its composition is not varied spatially or temporally. Representative bio-oil properties were sourced from the recent works of Oasmaa et al. [60-62]. The bio-oil properties are shown in Table 5.

The pyrolysis vapour and liquid bio-oil properties are subjected to errors associated with the estimation techniques and experimental values used for their computation. However, there is great confidence that the deviations from reality will not significantly affect the final results of the numerical model as the previously mentioned correlations and experimental values have been widely used and accepted by the chemical industry for several years.

\section{Numerical Model}

The commercial CFD package ANSYS Fluent 15 has been used as the computational platform for the simulation of the quenching column hydrodynamics. The modelling approach is based on the hybrid immiscible Eulerian model (VOF and Eulerian Multiphase model). The major advantage of this modelling approach over the standard VOF method which is developed by Hirt et al. [63] is that the solution of the conservation equations for each phase can provide information about the slip velocity at the interface of the two phases, which consequently leads to a more accurate prediction of the heat transfer computations. Moreover, there is no limitation in creating finer grids to capture finer volume fractions of the phases accurately. The governing equations for the numerical model are as follows:

Continuity equation for phase $p$

$$
\left(\frac{\partial}{\partial t}\left(a_{p} \rho_{p}\right)+\nabla \bullet\left(a_{p} \rho_{p} v_{p}\right)\right)=\left(\dot{m}_{q p}-\dot{m}_{p q}\right) .
$$


In Eq. (13), the mass source terms $\dot{m}_{p q} \& \dot{m}_{q p}$ correspond to mass transfer from phase $p$ to phase $q$ and vice versa. The mass transfer from vapour phase to the bio-oil phase corresponds to the sum of the individual species mass transferred to the bio-oil. This is calculated based on the vapour liquid equilibrium (VLE) condition as mentioned in section 3.1. In this study, the mass transfer between the coolant and other phases is neglected. The volume fraction $a_{p}$ is solved only for secondary phases. The primary phase volume fraction is calculated based on the fact that the sum of all phase volume fractions in the particular cell is equal to 1 as shown in Eq. (14)

$$
\sum_{p=1}^{n} \alpha_{p}=1 .
$$

The secondary phase volume equations are solved using explicit time discretisation which uses a finite-difference interpolation method. This method uses the previous time step volume fraction values for the calculations as given in Eq. (15)

$$
\frac{\alpha_{p}^{n+1} \rho_{p}^{n+1}-\alpha_{p}^{n} \rho_{p}^{n}}{\Delta t} V+\sum_{f}\left(\rho_{p} U_{f}^{n} \alpha_{p, f}^{n}\right)=\left[\sum_{q=1}^{n}\left(\dot{m}_{q p}-\dot{m}_{q p}\right)\right] V .
$$

Here, $\alpha_{p, f}^{n}$ is the face value of the $p^{\text {th }}$ volume fraction, whereas $U_{f}^{n}$ represents the volume flux through the faces. This was computed with a compressive scheme when the interface involves the liquid coolant. In the case of an interface between bio-oil and pyrolysis vapour, the calculations were performed by using a second order upwind scheme.

Momentum conservation equation for phase $p$

$$
\frac{\partial\left(a_{p} \rho_{p} v_{p}\right)}{\partial}+\nabla \bullet\left(a_{p} \rho_{p} v_{p} v_{p}\right)=-a_{p} \nabla p+\nabla \bullet \overline{\bar{\tau}}_{p}+a_{p} \rho_{p} \bar{g}+\bar{R}+F_{\sigma}+\bar{M}_{s, p},
$$

where $\overline{\bar{\tau}}_{p}$ is the stress-strain tensor, $\bar{R}$ is the interaction force between two phases given by

$$
\bar{R}=K_{p q}\left(\bar{v}_{p}-\bar{v}_{q}\right)
$$

where $K_{p q}$ is the interphase momentum exchange coefficient, defined as

$$
K_{p q}=\frac{\rho_{p q} f}{6 \tau_{p q}} d_{p} A_{i}
$$

where $f$ is the drag function, defined as $C_{D} \operatorname{Re} / 24, C_{D}$ is the drag coefficient based on the SchillerNaumann drag model [64]. and Re is the relative Reynolds number between the two phases.

$$
C_{D}=\left\{\begin{array}{cc}
24\left(1+0.15 \operatorname{Re}^{0.687}\right) / \operatorname{Re} & \operatorname{Re} \leq 1000 \\
0.44 & \operatorname{Re}>1000
\end{array}\right.
$$




$$
\operatorname{Re}=\frac{\rho_{p q}\left|\bar{v}_{p}-\bar{v}_{q}\right| d}{\mu_{p q}} .
$$

The term $\tau_{p q}$ used in Eq. (18) is the particulate relaxation time and is defined as

$$
\tau_{p q}=\frac{\rho_{p q} d^{2}}{18 \mu_{p q}} .
$$

The subscript $p q$ denotes the volume averaged properties for density and viscosity.

The interfacial area $A_{i}$ shown in Eq. (18) is estimated based on algebraic relation between interfacial area concentration and specific bubble diameter. This relationship explained in Eq. (22). The symmetry model is employed for the calculation of the interface between the coolant and vapours. In the case of vapours and bio-oil where some mist flow is expected, the particle model was used. However, for the computation of the drag forces, the symmetric drag model was utilised. This model is recommended when the dispersed phase in one region becomes a continuous phase in another region of the domain, this is true between vapours and liquid coolant.

$$
A_{i}=\left\{\begin{array}{lc}
\frac{6 \alpha_{i}}{d_{i}} & \text { particle model } \\
\frac{6 \alpha_{i}\left(1-\alpha_{i}\right)}{d_{i}} & \text { symmetric model }
\end{array} .\right.
$$

The diameter of the dispersed phase is represented by $d$, where in this work has been set equal to $0.0001 \mathrm{~m}$ which is one tenth of the minimum grid size. The term $F_{\sigma}$ used in Eq. (16) is a source term, which represents the surface tension forces at the interface. The formulation for the surface tension is based on the work of Brackbill et al.[65].

$$
F_{\sigma}=\sigma \frac{\rho_{p q} k_{p} \nabla a_{p}}{0.5\left(\rho_{p}+\rho_{q}\right)} .
$$

The surface tension coefficient $\sigma$ can be found in Table 5 together with the rest of the fluid properties. In Eq. 23, $k_{p}$ is defined as the curvature and is computed from the unit normal which is defined as the gradient of the volume fraction of the liquid phase.

The momentum source $\bar{M}_{s, p}$ is calculated based on the mass exchanged between the phases i.e. from vapour phase to bio-oil phase as shown in Eq. (24).

$$
\bar{M}_{s, p}=\dot{m}_{q p}\left(\bar{v}_{q}-\bar{v}_{p}\right) .
$$

Here $\dot{m}_{p q}$ is equal to the sum of all the individual species mass sources condensed to form the bio-oil and is computed as $\dot{m}_{p q}=\sum_{i} \dot{m}_{c}^{i}$.

In order to solve the conservation equations for individual chemical species within the vapour phase, the convection-diffusion equation of the $\mathrm{i}^{\text {th }}$ species as shown in Eq. (25) is used

$$
\frac{\partial}{\partial t}\left(\rho w^{i}\right)+\nabla \cdot \rho \bar{v} w^{i}=-\nabla \cdot \bar{J}^{i}+S^{i} .
$$


The diffusion flux $\vec{J}^{i}$ of the component $i$ is computed based on Fick's law which states that mass diffusion occurs due to concentration gradients.

The energy conservation for phase $p$ is given as

$$
\frac{\partial\left(a_{p} \rho_{p} h_{p}\right)}{\partial t}+\nabla \bullet\left(a_{p} \rho_{p} v_{p} h_{p}\right)=-a_{p} \frac{\partial p_{p}}{\partial t}+\overline{\bar{\tau}}_{p}: \nabla v_{p}-\nabla \bullet q_{p}+Q+H_{s, p}
$$

In Eq. (26), $q_{p}$ is the heat flux and $Q$ is the volumetric rate of energy transfer between two phases defined by

$$
Q=h_{p q}\left(T_{q}-T_{p}\right) .
$$

The heat transfer coefficient $h_{p q}$ between two phases was estimated based on the Ranz-Marshall correlation [66]. The heat source due to phase change $H_{s, p}$ mentioned in Eq. (26) is computed by

$$
H_{s, p}=\left\{\begin{array}{lr}
\sum_{i}\left(-\dot{m}_{c}^{i} H_{p}^{i}\right) & \text { for vapour phase } \\
\sum_{i} \dot{m}_{c}^{i}\left(H_{p}^{i}-\Delta H_{v}^{i}\right) & \text { for bio-oil phase }
\end{array}\right.
$$

The terms $H_{p}^{i} \& \Delta H_{v}^{i}$ are the enthalpy and latent heat of vaporisation of the species $i$.

Turbulence modelling has not been considered in this work since the Rayleigh number of the flow is well below the $10^{8}$ value. It has also been previously reported that laminar flow assumptions give better predictions for this type of flow [67]. However, the RNG k- $\varepsilon$ model has been also tested in the configuration, but the results did not show any significant difference.

\section{Model assumptions}

The implementation of the condensation model is based on the following assumptions.

I. The pyrolysis vapours together with the carrier gas nitrogen are treated as an ideal mixture. This is mainly due to the unavailability of the excess function data in the literature.

II. Fugacity coefficients are assumed as 1 . This assumption can be justified when the system is not under high pressures.

III. Uniform properties for the condensed bio-oil were assumed within the quenching column, whereas, for the bio-oil phase, a diffusive behaviour similar to a mist flow regime is assumed.

IV. Buoyancy induced laminar flow conditions were assumed inside the quenching column.

\section{Geometry}

Table 1 gives the existing experimental quenching column dimensions. The original configuration includes 9 stages (pairs) of discs and donuts. However, in order to assess the effects of the number of stages on the condensation of pyrolysis vapours, the hybrid design (Fig. 1) is modelled with 3, 5 and 9 stages respectively. The hybrid design is a combination of the Type 3 and Type 4 design variants as it is proposed in the part A of this study [44]. The main features of the hybrid design is that it offers the 
atomisation pattern present in the Type 3 variant at the bottom stage of the column, while it maintains the uniform flow characteristics of Type 4 variant for the rest of the column stages. This configuration provides a rapid cooling on the pyrolysis vapours as they enter the quenching column, while it minimises the pressure build up and eliminates any flooding phenomena. The respective computational grids comprise approximately $0.76,0.98$ and 1.4 million hexahedral cells for 3,5 and 9 stages with uniform spacing.

\section{Results \& Discussions}

\subsection{Optimization of the quenching column configuration}

As shown in Fig. 2, the hybrid design presents better inlet heat transfer characteristics than Type 4 variant whereas Type 3 variant provides the most rapid cooling at the inlet point mainly due to the increased heat transfer area resulting from the intense coolant atomisation. However, as the vapours flow through the first (i.e between 3.5 and $5.5 \mathrm{~cm}$ ) stage of the column, a sudden drop in the vapour temperature is observed in the hybrid design due to the combined effects of the coolant atomisation at the bottom donut plate and the uniform curtain flow from the upper disc plate. The vapour temperature is further decreased at the subsequent stages where it is eventually matched by the Type 3 variant towards the outlet of the column. The Type 4 variant is not able to provide as efficient vapour cooling as the Type 3 or the hybrid configuration at any stage of the column.

Observing the pressure variation in the three configurations (Fig. 3) one can see that the hybrid design presents the lowest overall pressure build up in the column compared to the Types 3 and 4 variants. Comparing the pressure build up as a pressure ratio of Types 3 and 4 to the hybrid design, one can observe that the pressure close to the inlet is higher in the hybrid configuration, something that is expected to positively affect the rapid vapour condensation at an early stage. The column pressure significantly increases at the later stages for Types 3 and 4 compared to the hybrid case. This pressure rise is expected to improve vapour to liquid conversion at the subsequent stages; however it makes the column more susceptible to flooding phenomena.

Overall, the hybrid design has been shown to provide better heat transfer performance with rapid vapour cooling. The increased vapour pressure at the early stages in the hybrid design facilitates better condensation, whereas its uniform hydrodynamic conditions and low pressure build up at the subsequent stages greatly overcome possible flooding phenomena. The condensation process is studied in different hybrid configurations consisting of 3,5 and 9 stages respectively (Fig. 4) in order to determine the optimum column size and vapour conversion efficiencies.

As shown in Fig. 5 the number of stages as well as the different pressure build ups in the different configurations do not have a significant impact on the maximum velocities at which the vapours travel through the column. It is observed that higher velocities are achieved close to the inlet with a magnitude ranging between $6-7 \mathrm{~m} / \mathrm{s}$, whereas a significant decrease $(2-3 \mathrm{~m} / \mathrm{s})$ is noted when the 
vapours flow through the disc and donut pairs on the column. Hence, the residence time and consequently the condensation time of the vapours will mainly depend on the geometrical aspects of the column rather than its two phase flow characteristics, which at steady state are almost identical for all three configurations.

\subsection{Phase change dynamics}

As shown in Fig. 6, there are considerable differences in the heat transfer and pressure build up characteristics among the various column configurations. It is evident that the higher the number of stages in the column, the more rapid the vapour cooling due to higher pressure build ups. The hydrodynamics behaviour of the column is only slightly affected by the different number of stages, whereas the condensed bio-oil distribution presents significant differences due to different heat transfer and pressure characteristics. It is evident from Fig. 7 that the average temperature difference between the 3-stage and the 9-stage configuration can reach up to approximately 8-10 $\mathrm{K}$ at individual stages. That is mainly reflected at the regions of $5-10 \mathrm{~cm}$ from the inlet as well as the region beyond $15 \mathrm{~cm}$ from the inlet. It is also worth noting that the coolant temperature was raised by 12 to $18 \mathrm{~K}$ within the quenching column between the coolant inlet and coolant outlet. The maximum temperature rise was observed in the 9-stage configuration. The pressure difference for the same regions can exceed $100 \mathrm{~Pa}$ as shown in Fig. 8. This will have significant implications on the final condensed fraction of the individual chemical compounds comprising the pyrolysis vapours in each column configuration.

As shown in Fig. 9, the phase change behaviour differs among the various compounds. Phase change from vapour to liquid takes place whenever the relative saturation of a specific compound exceeds unity. It is evident that in all configurations, the same 7 compounds (i.e. acetic acid, propionic acid, butyric acid, coniferyl alcohol, guaiacol, phenol and water) are condensed inside the column, however at different proportions. The different temperature and pressure build up characteristics in the column significantly affect the amount of the final condensed product. The 4 compounds that have been remained uncondensed in all column configurations are the aldehyde group (propanal, butanal, pentanal) as well as formic acid (i.e their maximum relative saturation does not exceed unity in any stage or configuration). In the carboxylic acids group, the acetic and propionic acid have been condensed to significant proportions. This result is in many aspects different compared to a previous study by the authors [43], where the condensation of pyrolysis vapours was investigated in an indirect contact heat exchanger. In that study, only traces of acetic and propionic acid were condensed due to a sudden change in pressure towards the outlet of the condenser. This was also validated by the experimental observations made under indirect contact condenser experimental conditions [68]. These results are also in good agreement with the observations of Westerhof et al. [13], where the light organic compounds (e.g. acetic acid) were primarily collected in the second condenser. It needs to be noted though that different operating conditions and different types of condensers (spray columns) 
were used in that study. It is clearly evident that the lower temperature and especially the greater vapour pressure build up in the quenching column significantly promote the phase change of the acidic components (35 to $62 \%$ for acetic acid and 66 to $81 \%$ for propionic acid as shown in Table 6). In both studies however, the highly volatile compounds such as formic acid and the aldehyde group have not been condensed at all. This is also evident from recent experimental works [23] conducted at Aston university where the direct contact cooling was adopted. The results clearly show that the pH values of the bio-oil collected from the quenching column was higher than the bio-oil collected from the dry ice condensers. This trend of increasing acid number in subsequent stages of condensers was clearly highlighted in Pollard et al.'s [17] experimental works on bio-oil recovery with stage fractions. It is worth to note that compound condensation continues to take place until the outlet of the column for all configurations. The only compound that shows significant difference in its thermodynamic behaviour between the 5-stage and the 9-stage configurations is the butyric acid. The mole fraction ratio in the vapour mixture (Fig. 10) shows how the concentration of each of the pyrolysis vapours compound changes relative to its concentration at the inlet, as the various compounds condense in the column. A value of zero in the relative mole fraction graph indicates complete conversion of that compound. As shown in Figs. 9 and 10, butyric acid is completely condensed only in the 9-stage configuration due to the increased pressure build up in the column. This shows the significant role that pressure variations can play in the liquid collection system. Taking into account that coolant temperatures present a lower limit and can significantly limit phase change, the design of quenching columns needs to focus on pressure control for the optimisation of the final liquid yield. In this study, butyric acid is the perfect example of such influence of the system pressure on the thermodynamic behaviour of selected compounds. However, the upper limit for pressure build up in the column is dictated by flooding phenomena, as described in the part A of this study. Excessive condensation of the rest six compounds, with nearly over $50 \%$ in all configurations, is also observed as shown in Table 6 with acetic acid being the only exception in the 3-stage configuration with $35 \%$ conversion. Condensation of acetic acid was also observed in the later stages of condensers in the study of Pollard et al. [17] which displays a similar trend with this study.

The total and maximum enthalpy of condensation per segment, shown in Fig. 11, is directly related to the condensed mass of each species and they follow a similar trend. Hence, the enthalpy source is directly correlated with the mass source. As shown in Fig. 11, the higher fraction of vapour conversion occurs within the bottom 3 stages of each column configuration. This is an expected outcome if one considers that the partial pressure of the vapour compounds is significantly higher at the inlet of the column. However, the mass source of each species varies significantly depending on the degree of volatility of the corresponding compound. It is clear that compounds with lower volatility (i.e. coniferyl alcohol, phenol, guaiacol) are nearly completely condensed even at the first stage of the column, whereas the fraction with higher volatility is only partially condensed at the end 
of the third stage. As mentioned earlier, butyric acid behaves differently in the 9-stage configuration due to higher pressure build up in the column. It is shown (Fig. 11) that in the 3- and 5- stage configurations it is only partially condensed at the end of the third stage, whereas it is completely converted at the end of the first stage in the 9-stage configuration. A significant amount of water is also converted primarily in the bottom 2 stages of the column in all configurations, while its overall conversion is only slightly affected by the number of stages in the column (i.e. only $6 \%$ difference between the 3-stage and 9-stage configurations). The rate of water condensation is also found to be in line with the predictions of the thermodynamic model of Westerhof et al. [13], where limited condensation is observed at temperatures below $20^{\circ}$ C. Moreover, water condensation significantly increases when the condenser temperature is kept below $70^{\circ} \mathrm{C}$ [31].

The enthalpy of vaporization values are embedded into the solver as energy source terms and are subtracted from the bio-oil phase. As it is the case for the mass sources of the individual compounds, the higher total as well as maximum enthalpy values are attributed to the lower volatility compounds and water, where an order of magnitude difference is observed with the rest of the condensed components. Despite its complete conversion in the 9-stage configuration, butyric acid's contribution to the total and maximum enthalpies of condensation is still low due to its higher vapour pressure.

\section{Conclusions}

A species transport model was implemented within the immiscible Eulerian multiphase approach to model the pyrolysis vapour condensation in a disc and donut quenching column. It was found that the design of this equipment needs to be compromised between two fundamental factors; the hydrodynamic performance, which will ensure the continuous operation of the column and the maximum degree of vapour to liquid conversion. In the part A of this study, it was shown that gas pressure build up can result in flooding phenomena which will eventually affect the capacity and gas flow rate in the column. Different design variants to overcome the flooding issues were proposed. In this study, it was shown that the lower coolant temperatures and higher pressure build up in the column promote the condensation of the higher volatility compounds. However, the limiting factor will always be the desired pyrolysis vapours conversion and hydrodynamic stability of the column.

In the current study, it was shown that the lower volatility compounds were rapidly and totally condensed in all three different column configurations. However, significant differences in the final degree of conversion were observed in the higher volatility compounds. Partial condensation was observed for the acidic components apart from formic acid which was not condensed at any configuration. It was shown that the higher the pressure build up in the column, due to the increased number of stages, can significantly aid the conversion of the compounds with higher volatility, such as butyric acid. The highly volatile compounds such as the aldehyde group as well as formic acid 
462 were not condensed at any column configuration, leading to the conclusion that secondary low 463 temperature condensers will be required in the system.

464 It has to be noted that the presented model can be used for the design and optimisation of any type of 465 heat exchanger used for the condensation of fast pyrolysis vapours. However, the fluid dynamic and 466 heat transfer characteristics which will eventually affect the equilibrium properties of the selected 467 compounds will be specific to the condenser under study. The results presented in this study are 468 specific to the proposed quenching column and cannot be extrapolated to other types of condensers.

469 Acknowledgements

470 The authors gratefully acknowledge the financial support for this work by the UK Engineering and 471 Physical Sciences Research Council (EPSRC) project grant: EP/K036548/1 and the EU FP7 IPACTS 472 (268696) and iComFluid Projects (312261). 
473 Nomenclature

$474 \quad$ Latin symbols

$475 \quad A_{c} \quad$ Curtain area, $\mathrm{m}^{2}$

$476 A_{w} \quad$ Window area, $\mathrm{m}^{2}$

$477 \quad C_{D} \quad$ Drag coefficient

$478 \quad C_{p_{m}}$ Mixture heat capacity $\mathrm{J} / \mathrm{kg} \mathrm{K}$

$479 \quad d \quad$ Droplet/ bubble diameter, $\mathrm{m}$

$480 \quad f \quad$ Drag function

$481 f_{0}, f_{1}$ Functions in the three parameter corresponding state equation

$482 f_{l}^{i} \quad$ Liquid fugacity, $\mathrm{Pa}$

$483 \quad f_{v}^{i} \quad$ Vapour fugacity, $\mathrm{Pa}$

$484 \quad F_{\sigma} \quad$ Surface tension force, $\mathrm{N} / \mathrm{m}^{3}$

$485 g \quad$ Gravitational acceleration, $\mathrm{m} / \mathrm{s}^{2}$

$486 h \quad$ Specific enthalpy of the phase, $\mathrm{J} / \mathrm{kg}$

$487 \quad H_{p}^{i} \quad$ Enthalpy of the species

$488 H_{s, p} \quad$ Latent heat source, $\mathrm{W} / \mathrm{m}^{3}$

$489 \quad H_{v}^{i} \quad$ Heat of vaporisation or latent heat, $\mathrm{J} / \mathrm{kg}$

$490 \quad k_{m} \quad$ Mixture thermal conductivity W/ m K

$491 \quad K_{p q} \quad$ Interphase momentum exchange coefficient, $\mathrm{kg} / \mathrm{m}^{3} \mathrm{~s}$

$492 \quad k_{p} \quad$ Curvature

$493 \quad M^{i} \quad$ Mole fraction, $\mathrm{g} / \mathrm{mol}$

$494 \quad M_{m} \quad$ Mixture molecular weight, $\mathrm{g} / \mathrm{mol}$

$495 \bar{M}_{s, p} \quad$ Momentum source vector, $\mathrm{N} / \mathrm{m}^{3}$

$496 \quad \dot{m}_{c}^{i} \quad$ Mass condensed, $\mathrm{kg} / \mathrm{m}^{3} \mathrm{~s}$

$497 \quad \dot{m}_{q p} \quad$ Mass transfer rate between phase $\mathrm{q}$ to phase $\mathrm{p}, \mathrm{kg} / \mathrm{m}^{3} \mathrm{~s}$

$498 \quad n \quad$ Unit normal

$499 \quad p \quad$ Pressure, $\mathrm{Pa}$

$500 \quad P \quad$ Pressure, $\mathrm{Pa}$

$501 \quad P^{i} \quad$ Partial pressure, $\mathrm{Pa}$

$502 P_{C}^{i} \quad$ Critical pressure, bar

$503 \quad P_{c m} \quad$ Mixture critical pressure, $\mathrm{Pa}$ 


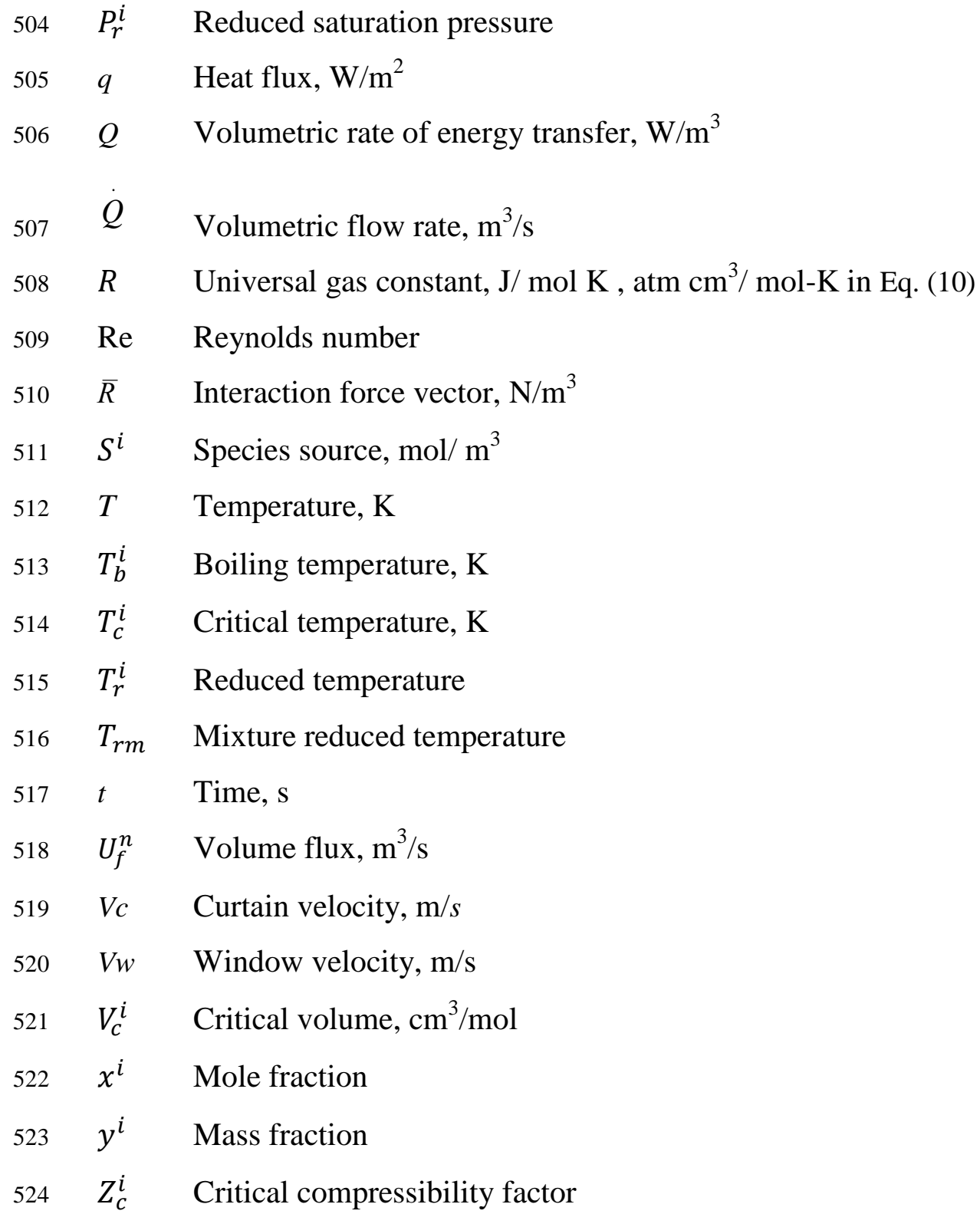


$535 \quad \tau \quad$ Particulate relaxation time, $\mathrm{s}$

$536 \quad \tau^{i} \quad$ Inverse of the reduced temperature

$537 \quad \overline{\bar{\tau}} \quad$ Stress tensor, $\mathrm{N} / \mathrm{m}^{2}$

$538 \quad \phi^{i} \quad$ Fugacity coefficient

$539 \phi_{\text {sat }}^{i} \quad$ Fugacity coefficient at saturation condition

$540 \quad \omega^{i} \quad$ Acentric factor

$541 \quad$ Subscripts

$542 \quad b \quad$ Properties at boiling point

$543 \quad c \quad$ Critical properties

$544 \quad f \quad$ face index

$545 \quad p, q \quad$ Phase index

$546 \quad p q \quad$ Volume averaged properties

$547 \quad l \quad$ Liquid

$548 \quad g \quad$ Gas

$549 \quad m \quad$ Vapour mixture

550 Superscripts

$551 \quad i \quad \mathrm{i}^{\text {th }}$ species 


\section{References}

[1] UN-FCCC/CP/2009/L.7, Copenhagen Accord, 18 December 2009.

[2] ANEFA. Forest biomass: opportunity and value. National association of forestry, agricultural and environment enterprises, 2011.

[3] S. Rafael , L. Tarelho, A. Monteiro, E. Sá , A.I. Miranda , C. Borrego, M. Lopes, Impact of forest biomass residues to the energy supply chain on regional air quality, Science of The Total Environment 505 (2015) 640-648.

[4] R.P. Anex, A. Aden, F.K. Kazi, J. Fortman, R.M. Swanson, M.M. Wright, J.A. Satrio, R.C. Brown, D.E. Daugaard, A. Platon, G. Kothandaraman, D.D. Hsu, A. Dutta, Techno-economic comparison of biomass-to-transportation fuels via pyrolysis, gasification, and biochemical pathways, Fuel 89 (2010) S29-S35

[5] A.V. Bridgwater, G.V.C. Peacock, Fast pyrolysis processes for biomass, Renewable and Sustainable Energy Reviews 4 (2000) 1-74.

[6] J. Lehto, A. Oasmaa, Y. Solantausta, M. Kytö, D. Chiaramonti, Fuel oil quality and combustion of fast pyrolysis bio-oil, VTT Technology 87 (2013).

[7] A.V. Bridgwater, Review of fast pyrolysis of biomass and product upgrading, Biomass and Bioenergy 38 (2012) 68-94.

[8] C. Paenpong, S. Inthidech, A. Pattiya, Effect of filter media size, mass flow rate and filtration stage number in a moving-bed granular filter on the yield and properties of bio-oil from fast pyrolysis of biomass, Bioresource Technology 139 (2013) 34-42.

[9] M. Asadullah, N.S.A. Rasid, S.A.S.A. Kadir, A. Azdarpour, Production and detailed characterization of bio-oil from fast pyrolysis of palm kernel shell, Biomass and Bioenergy 59 (2013) 316-324.

[10] S.W. Kim, B.S. Koo, J.W. Ryu, J.S. Lee, C.J. Kim, D.H. Lee, G.R. Kim, S. Choi, Bio-oil from the pyrolysis of palm and Jatropha wastes in a fluidized bed, Fuel Processing Technology 108 (2013) 118-124.

[11] H.J. Park, Y.K. Park, J.S .Kim, Influence of reaction conditions and the char separation system on the production of bio-oil from radiata pine sawdust by fast pyrolysis, Fuel Processing Technology 89 (2008) 797-802.

[12] Hameed B. Mahood, Alasdair.N. Campbell, Rex.B. Thorpe, Adel.O. Sharif, Experimental measurements and theoretical prediction for the volumetric heat transfer coefficient of a three- 
phase direct contact condenser, International Communications in Heat and Mass Transfer, 66, (2015), 180-188.

[13] R.J.M. Westerhof, N.J.M. Kuipers, S.R.A. Kersten, W.P.M. van Swaaij, Controlling the Water Content of Biomass Fast Pyrolysis Oil, Industrial \& Engineering Chemistry Research 46 (2007) 9238-9247.

[14] R. J. M. Westerhof, D. W. F. Brilman, M. Garcia-Perez, Z. Wang, S. R. G. Oudenhoven, W. P. M. van Swaaij, S. R. A. Kersten, Fractional condensation of biomass pyrolysis vapors., Energy \& Fuels 25(2011) 1817-1829.

[15] Yin R., Liu R., Mei Y. Fei, W. Sun X., Characterization of bio-oil and bio-char obtained from sweet sorghum bagasse fast pyrolysis with fractional condensers, Fuel 112 (2013) 96-104.

[16] Boateng A. A., Mullen C. A., Goldberg N., Hicks K. B., Jung H.-J.G., Lamb J.F.S., Production of bio-oil from alfalfa stems by fluidized-bed fast pyrolysis, Industrial and Engineering Chemistry Research, 46 (2008), 4115-4122.

[17] A.S. Pollard, M.R. Rover, R.C. Brown, Characterization of bio-oil recovered as stage fractions with unique chemical and physical properties, Journal of Analytical and Applied Pyrolysis, 93 (2012), 129-138.

[18] Marjorie R. Rover, Patrick A. Johnston, Lysle E. Whitmer, Ryan G. Smith, Robert C. Brown, The effect of pyrolysis temperature on recovery of bio-oil as distinctive stage fractions, Journal of Analytical and Applied Pyrolysis, 105 ( 2014) , 262-268.

[19] N. Jendoubi, F. Broust, J.M. Commandre, G. Mauviel, M. Sardin, J. Lédé, Inorganics distribution in bio oils and char produced by biomass fast pyrolysis: The key role of aerosols, Journal of Analytical and Applied Pyrolysis, 92 ( 2011), 59-67.

[20] Jacques Lédé, François Broust, Fatou-Toutie Ndiaye, Monique Ferrer, Properties of bio-oils produced by biomass fast pyrolysis in a cyclone reactor, Fuel, 86(2007), 1800-1810.

[21] Williams P.T., Brindle A.J., Temperature selective condensation of tyre pyrolysis oils to maximise the recovery of single ring aromatic compounds , Fuel, 82 (2003), 1023-1031.

[22] Roel J. M. Westerhof, D. Wim F. Brilman, Manuel Garcia-Perez, Zhouhong Wang, Stijn R. G. Oudenhoven, Wim P. M. van Swaaij, Sascha R. A. Kersten, Fractional Condensation of Biomass Pyrolysis Vapors, Energy \& Fuels , 25(2011), 1817-1829.

[23] Abba Sani Kalgo, The Development and Optimisation of a Fast Pyrolysis Process for Bio-oil Production, Ph.D. Thesis, Bio-energy Research Group, Aston University, 2011. 
[24] C.E. Greenhalf, D.J. Nowakowski, A.B. Harms, J.O. Titiloye, A.V. Bridgwater, A comparative study of straw, perennial grasses and hardwoods in terms of fast pyrolysis products, Fuel, 108 (2013), 216-230

[25] C. Gustavsson , L. Nilsson , Co-production of pyrolysis oil in district heating plants: Systems analysis of dual fluidized-bed pyrolysis with sequential vapor condensation, Energy \& Fuels 27 (2013) 5313-5319

[26] V. Karlsson \& L. Nilsson Co-production of pyrolysis oil and district cooling in biomass-based CHP plants: Utilizing sequential vapour condensation heat as driving force in an absorption cooling machine, Applied Thermal Engineering 79 (2015) 9-16.

[27] A.V. Bridgwater, Renewable fuels and chemicals by thermal processing of biomass, Chemical Engineering Journal 91 (2003) 87-102

[28] J.P. Diebold, Preliminary Results in the Fast Pyrolysis of Biomass to Lower Olefins, Petroleum Chemistry division of ACS Symposium on Alternate Feed stocks for Petrochemicals.

[29] A.G.W. Bradbury, Y. Sakai, F. Shafizadeh, A Kinetic Model for Pyrolysis of Cellulose, Journal of Applied Polymer Science 23 (1979) 3271-3280.

[30] Henley E. J., Seader J. D., Equilibrium-Stage Separation Operations in Chemical Engineering; Wiley: New York, 1981.

[31] Tumbalam Gooty A., Li D., Briens C., Berruti F., Fractional condensation of bio-oil vapors produced from birch bark pyrolysis, eparation and Purification Technology, 124(2014), 81-88.

[32] Tumbalam Gooty A., Li D., Berruti F., Briens C., Kraft-lignin pyrolysis and fractional condensation of its bio-oil vapors, (Journal of Analytical and Applied Pyrolysis, 106 (2014), $33-40$.

[33] G. Gesit, K. Nandakumar, K. T. Chuang, CFD Modeling of Flow Patterns and Hydraulics of Commercial-Scale Sieve Trays, AIChE Journal 49 (2003) 910-924.

[34] A. Zarei, S.H. Hosseini, R. Rahimi, CFD study of weeping rate in the rectangular sieve trays, Journal of the Taiwan Institute of Chemical Engineers 44 (2013) 27-33.

[35] A. Zarei, S.H. Hosseini, R. Rahimi, CFD and experimental studies of liquid weeping in the circular sieve tray columns, Chemical Engineering Research and Design 91 (2013) 2333-2345.

[36] A. Alizadehdakhel, M. Rahimi, A.A. Alsairafi, CFD and experimental studies on the effect of valve weight on performance of a valve tray column, Computers \& Chemical Engineering 34 (2010) 1-8. 
[37] K. Papadikis, S. Gu, A.V. Bridgwater, Computational modelling of the impact of particle size to the heat transfer coefficient between biomass particles and a fluidised bed, Fuel Processing Technology 91 (2010) 68-79.

[38] P. Mellin, E. Kantarelis, W. Yang, Computational fluid dynamics modeling of biomass fast pyrolysis in a fluidized bed reactor, using a comprehensive chemistry scheme, Fuel 117 (2014) 704-715.

[39] A. Sharma, V. Pareek, D. Zhang, Biomass pyrolysis-A review of modelling, process parameters and catalytic studies, Renewable and Sustainable Energy Reviews, 50 (2015), 10811096.

[40] X. Yu, Y. Makkawi, R. Ocone, M. Huard, C. Briens, F. Berruti, A CFD study of biomass pyrolysis in a downer reactor equippedwith a novel gas-solid separator - I: hydrodynamic performance, Fuel Processing Technology 126 (2014) 366-382.

[41] X. Yu, Y. Makkawi, R. Ocone, M. Huard, C. Briens, F. Berruti, A CFD study of biomass pyrolysis in a downer reactor equippedwith a novel gas-solid - II: Thermochemical performance and products, Fuel Processing Technology 133 (2015) 51-63.

[42] K. Papadikis, S. Gu, A.V. Bridgwater, Eulerian model for the condensation of pyrolysis vapors in a water condenser, Energy \& Fuels 25 (2011) 1859-1868.

[43] V.S. Kiran Kumar Palla, K. Papadikis, S. Gu, A numerical model for the fractional condensation of pyrolysis vapours, Biomass and Bioenergy 74 (2015) 180-192.

[44] V. S. Kiran Kumar Palla, K. Papadikis, S. Gu, Computational modelling of the condensation of fast pyrolysis vapours in a quenching column. Part A: Hydrodynamics, heat transfer and design optimisation, Fuel Processing Technology 131 (2015) 59-68.

[45] G.V.C. Peacocke, A.V. Bridgwater, Ablative plate pyrolysis of biomass for liquids, Biomass and Bioenergy 7 (1995) 147-154.

[46] N. Robinson, Design, modelling and construction of a novel ablative fast pyrolysis reactor and product collection system, PhD thesis, Aston University, U.K (2000).

[47] A.J. Toft, A comparison of integrated biomass to electricity systems, PhD thesis, Aston University, U.K (1996).

[48] E. Butler, G. Devlin, D. Meier, K. McDonnelle, Characterisation of spruce, salix, miscanthus and wheat straw for pyrolysis applications. Bioresource Technology 131 (2013) 202-209.

[49] M. Garcia-Perez, A. Chaala, H. Pakdel, D. Kretschmer, C. Roy, Characterization of bio-oils in chemical families, Biomass and Bioenergy, 31(2007), 222-242. 
[50] J. Brett, A. Ooi, J. Soria, The effect of internal diffusion on an evaporating bio-oil droplet - The chemistry free case, Biomass and Bioenergy 34(8) (2010) 1134-1140.

[51] W.L.H. Hallett, N.A. Clark, A model for the evaporation of biomass pyrolysis oil droplets, Fuel 85 (4) (2006) 532-544.

[52] B.E. Poling, J.M. Prauznitz, J.P. O’Connell, The properties of gases and liquids. Fifth edition, McGraw-Hill, 2001.

[53] J. Marrero-Morejon, E. Pardillo-Fontdevila, Estimation of pure compound properties using group-interaction contributions, AIChE Journal 45(3) (1999) 615-621.

[54] K.H. Mejbri, A. Bellagi, Corresponding states correlation for the saturated vapor pressure of pure fluids. Thermochimica Acta, 436(1-2) (2005) 140-149.

[55] D.E. Dean, L.I. Stiel, The viscosity of non-polar gas mixtures at moderate and high pressures. AIChE Journal 11(3) (1965) 526-532.

[56] T-H. Chung, M. Ajlan, L.L. Lee, K.E. Starling, Generalized multiparameter correlation for nonpolar and polar fluid transport properties, Industrial \& Engineering Chemistry Research 27(4) (1988) 671-679.

[57] R.C. Reid, J.M. Prauznitz, T.K. Sherwood, The properties of gases and liquids. McGraw-Hill, 1977.

[58] D.R. Stull, E.F. Jr. Westrum, G.C. Sinke, The chemical thermodynamics of organic compounds, John Wiley \& Sons, Inc., 1969.

[59] K.S. Pitzer, D.Z. Lippmann, R.F. Jr. Curl, C.M. Huggins, D.E. Petersen, The Volumetric and Thermodynamic Properties of Fluids. II. Compressibility Factor, Vapor Pressure and Entropy of Vaporization, Journal of the American Chemical Society 77(13) (1955) 3433-3440.

[60] A. Oasmaa, C. Peacocke, A guide to physical property characterisation of biomass-derived fast pyrolysis liquids, VTT Publications, VTT technical research centre of Finland, ESPOO, 2001.

[61] A. Oasmaa, B. Van De Beld, P. Saari, D.C. Elliot, Y. Solantausta, Norms, Standards, and Legislation for Fast Pyrolysis Bio-oils from Lignocellulosic Biomass, Energy \& Fuels 29(4) (2015) 2471-2484.

[62] A. Oasmaa, C. Peacocke, S. Gust, D. Meier, R. McLellan, Norms and Standards for Pyrolysis Liquids. End-User Requirements and Specifications, Energy \& Fuels 19(5) (2005) 2155-2163.

[63] C.W. Hirt, B.D. Nichols, Volume of fluid (VOF) method for the dynamics of free boundaries, Journal of Computational Physics 39 (1981) 201-225. 
[64] L. Schiller, A.Z. Naumann, Uber die grundlegenden berechungen bei der schwerkraftaufbereitung, Verein Deutsher Ingenieure 77 (1933) 318-321.

[65] J.U. Brackbill, D.B. Kothe, C. Zemach, A continuum method for modeling surface tension Journal of Computational Physics 100 (1992) 335-354.

[66] W. Ranz, W. Marshall, Evaporation from drops, Part II , Chemical engineering progress 48 (1952) 173-180.

[67] L. Raynal, A. Royon-Lebeaud, A multi-scale approach for CFD calculations of gas-liquid flow within large size column equipped with structured packing, Chemical Engineering Science 62 (2007) $7196-7204$.

[68] A. Fivga, Comparison of the effect of pre-treatment and catalysts on liquid quality from fast pyrolysis of biomass. Ph.D. Thesis, Bio-energy Research Group, Aston University, 2011. 
Tables:

$720 \quad$ Table 1

$721 \quad$ Design specifications.

$\begin{array}{ll}\text { Volumetric } & \text { Temperature } \\ \text { Flow rate } & \left(\mathrm{m}^{3} / \mathrm{s}\right)\end{array}$

Column

Diameter

inner Disc Spacing

annular diameter

Between

Number

Number

(cm)

diameter $(\mathrm{cm})$

donut

(cm)

(cm)

Experiment

8

3 stages

0.044

400

9.7

3.4

7.7

2

5 stages

9 stages

9

722 Table 2

723 Chemical compounds in the pyrolysis vapour and their properties.

\begin{tabular}{|c|c|c|c|c|c|c|c|}
\hline $\begin{array}{l}\text { Chemical } \\
\text { compound }\end{array}$ & $\begin{array}{l}\text { Initial } \\
\text { Volume } \\
\text { fraction * }\end{array}$ & $\begin{array}{l}\text { Molar mass } \\
(\mathrm{g} / \mathrm{mol})\end{array}$ & $\begin{array}{l}\text { Critical } \\
\text { Temperature } \\
(\mathrm{K})\end{array}$ & $\begin{array}{l}\text { Critical } \\
\text { pressure } \\
\text { (atm) }\end{array}$ & $\begin{array}{l}\text { Critical } \\
\text { volume } \\
\left(\mathrm{cm}^{3} / \mathrm{mol}\right)\end{array}$ & $\begin{array}{l}\text { Acentric } \\
\text { factor }\end{array}$ & $\begin{array}{l}\text { Critical } \\
\text { compressibility } \\
\text { factor }\end{array}$ \\
\hline Acetic acid & 0.037 & 60.05 & 594 & 57.1 & 171 & 0.454 & 0.2 \\
\hline Butanal & 0.109 & 72.11 & 524 & 40 & 278 & 0.352 & 0.26 \\
\hline Butyric acid & 0.011 & 88.11 & 628 & 52 & 292 & 0.67 & 0.295 \\
\hline Coniferyl alcohol & 0.19 & 180.2 & 569.9 & 33.6 & 482 & 1.155 & 0.346 \\
\hline Formic acid & 0.042 & 46.02 & 580 & 57.34 & 120 & 0.368 & 0.1445 \\
\hline Guaiacol & 0.108 & 124.14 & 696.8 & 46.613 & 338 & 0.563 & 0.275 \\
\hline Pentanal & 0.021 & 86.13 & 554 & 35 & 333 & 0.4 & 0.26 \\
\hline Phenol & 0.054 & 94.11 & 694.2 & 60.5 & 229 & 0.44 & 0.24 \\
\hline Propanal & 0.144 & 58.08 & 496 & 47 & 223 & 0.313 & 0.26 \\
\hline Propionic acid & 0.017 & 74.08 & 612 & 53 & 230 & 0.536 & 0.242 \\
\hline Water Vapour & 0.267 & 18.01 & 647.3 & 217.6 & 56 & 0.344 & 0.229 \\
\hline
\end{tabular}


Table 3

727 Coefficients of Eqs. 2 and 3.

\begin{tabular}{ll}
$k$ & $\gamma_{k}$ \\
\hline 1 & -5.53357241 \\
2 & 11.0210515 \\
3 & -0.51243147 \\
4 & -10.6722729 \\
5 & 29.4364927 \\
6 & -0.44101891 \\
\hline
\end{tabular}

Table 4

$730 \quad$ Heat capacities of individual components present in pyrolysis vapours.

\begin{tabular}{|c|c|c|c|}
\hline \multirow[b]{2}{*}{ Chemical compound } & \multicolumn{3}{|c|}{$C_{p}=\mathrm{A}_{1}+\mathrm{A}_{2} T+\mathrm{A}_{3} T^{2}$} \\
\hline & $\mathrm{A}_{1}$ & $\mathrm{~A}_{2}$ & $\mathrm{~A}_{3}$ \\
\hline Acetic acid & 195.74849 & 3.5237048 & -0.001545339 \\
\hline Butanal & 245.97362 & 4.4604585 & -0.001734686 \\
\hline Butyric acid & 229.03995 & 3.9854485 & -0.001549761 \\
\hline Coniferyl alcohol & 527.97236 & 3.1066709 & -0.000768719 \\
\hline Formic acid & 326.7 & 2.5160000 & -0.00105 \\
\hline Guaiacol & 531.24523 & 3.0758568 & -0.000739824 \\
\hline Pentanal & 202.39221 & 4.7575163 & -0.001883003 \\
\hline Phenol & -158.75528 & 4.9638417 & -0.002442437 \\
\hline Propanal & 240.36658 & 4.2292475 & -0.001671269 \\
\hline Propionic acid & 164.9201 & 4.0156030 & -0.001735477 \\
\hline Water Vapour & 1779.0173 & 0.1717701 & 0.000362651 \\
\hline
\end{tabular}


Table 5

$735 \quad$ Fluid properties.

\begin{tabular}{|c|c|c|c|c|c|}
\hline Fluid & Density $\left(\mathrm{kg} / \mathrm{m}^{3}\right)$ & $\begin{array}{l}\text { Specific heat capacity } \\
(\mathrm{J} / \mathrm{kg} \cdot \mathrm{K})^{*}\end{array}$ & $\begin{array}{l}\text { Thermal } \\
\text { conductivity } \\
(\mathrm{W} / \mathrm{m} \cdot \mathrm{K})^{*}\end{array}$ & $\begin{array}{l}\text { Dynamic viscosity } \\
(\mathrm{kg} / \mathrm{m} \cdot \mathrm{s})^{*}\end{array}$ & $\begin{array}{l}\text { Surface } \\
\text { tension } \\
(\mathrm{N} / \mathrm{m})\end{array}$ \\
\hline Nitrogen & Ideal gas & $\begin{array}{l}979.043+0.4179639 \mathrm{~T} \\
-0.001176279 \mathrm{~T}^{2}+ \\
1.674394 \mathrm{e}-06 \mathrm{~T}^{3}- \\
7.256297 \mathrm{e}-10 \mathrm{~T}^{4}\end{array}$ & $\begin{array}{l}0.004737109+ \\
7.271938 \mathrm{e}-05 \mathrm{~T}- \\
1.122018 \mathrm{e}-08 \mathrm{~T}^{2}+ \\
1.454901 \mathrm{e}-12 \mathrm{~T}^{3}- \\
7.8712 \mathrm{e}-17 \mathrm{~T}^{4}\end{array}$ & $\begin{array}{l}7.473306 \mathrm{e}-06+ \\
4.083689 \mathrm{e}-08 \mathrm{~T}- \\
8.244628 \mathrm{e}-12 \mathrm{~T}^{2}+ \\
1.305629 \mathrm{e}-15 \mathrm{~T}^{3}- \\
8.177936 \mathrm{e}-10 \mathrm{~T}^{4}\end{array}$ & \\
\hline Octane & 722.32 & 2127.812 & 0.13415 & 0.000769 & 0.024088 \\
\hline Bio-oil & 1200 & 3200 & 0.386 & $\begin{array}{l}12.9881-0.080204 * \mathrm{~T} \\
+0.000124 * \mathrm{~T}^{2}\end{array}$ & - \\
\hline
\end{tabular}

*Note: Temperature $\mathrm{T}$ mentioned in the table is in $\mathrm{K}$.

Table 6

738 Conversion of pyrolysis vapours at different quenching column configurations.

\section{Degree of Conversion (\% of inlet mass fraction)}

\begin{tabular}{|c|c|c|c|}
\hline \multirow{2}{*}{ Chemical Compound } & \\
\hline & 3 -stages & 5-stages & 9-stages \\
\hline Acetic Acid & 35 & 57 & 62 \\
\hline Butanal & 0 & 0 & 0 \\
\hline Butyric Acid & 92 & 95 & 100 \\
\hline Coniferyl Alcohol & 100 & 100 & 100 \\
\hline Formic Acid & 0 & 0 & 0 \\
\hline Guaiacol & 100 & 100 & 100 \\
\hline Pentanal & 0 & 0 & 0 \\
\hline Phenol & 99 & 99 & 99 \\
\hline Propanal & 0 & 0 & 0 \\
\hline Propionic Acid & 66 & 78 & 81 \\
\hline Water & 85 & 90 & 91 \\
\hline
\end{tabular}




\section{List of figures:}

1. Hybrid design of the quenching column.

2. Average temperature plot-hydrodynamic models.

3. Average pressure ratio plot - hydrodynamic models.

4. Donut and disc configuration for 3,5 and 9 stage models.

5. Maximum vapour velocity plot $-3,5$ and 9 stage models.

6. Contours of temperature, pressure and volume fractions - 3,5 and 9 stage models.

7. Average temperature plot $-3,5$ and 9 stage models.

8. Average pressure plot $-3,5$ and 9 stage models.

9. Relative saturation.

10. Relative mole fraction.

11. Total and maximum enthalpies of condensation per segment. 


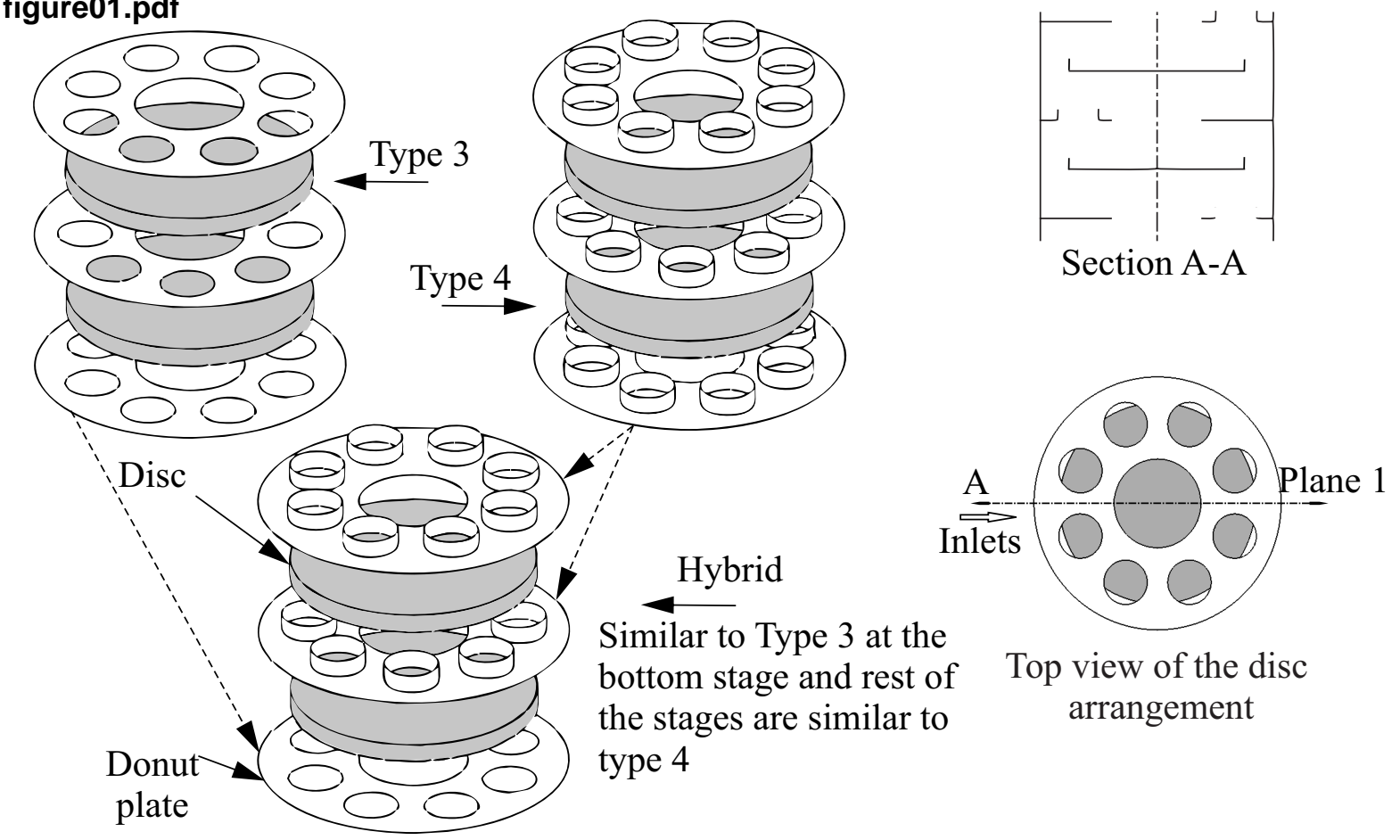


figu6e02-pdf

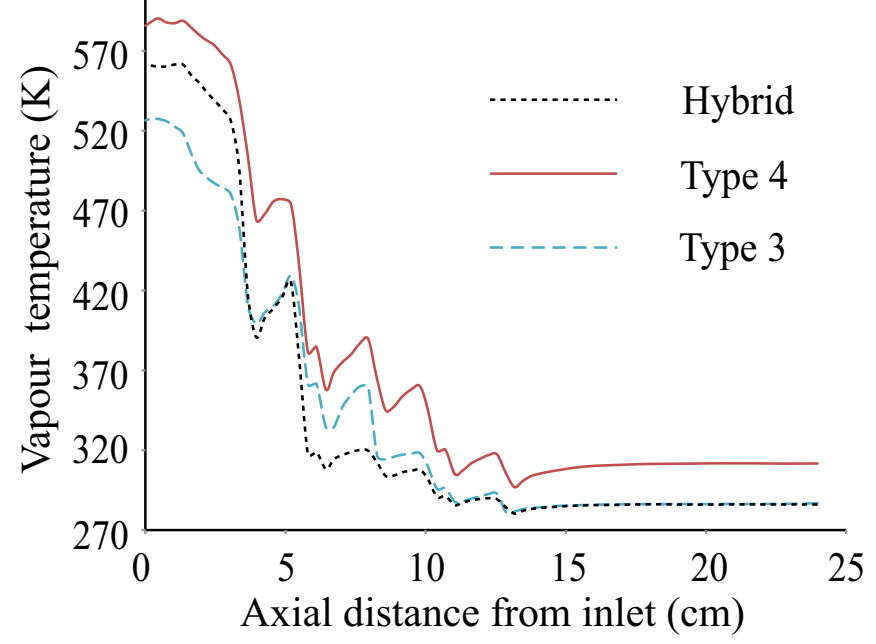


figure03.pdf

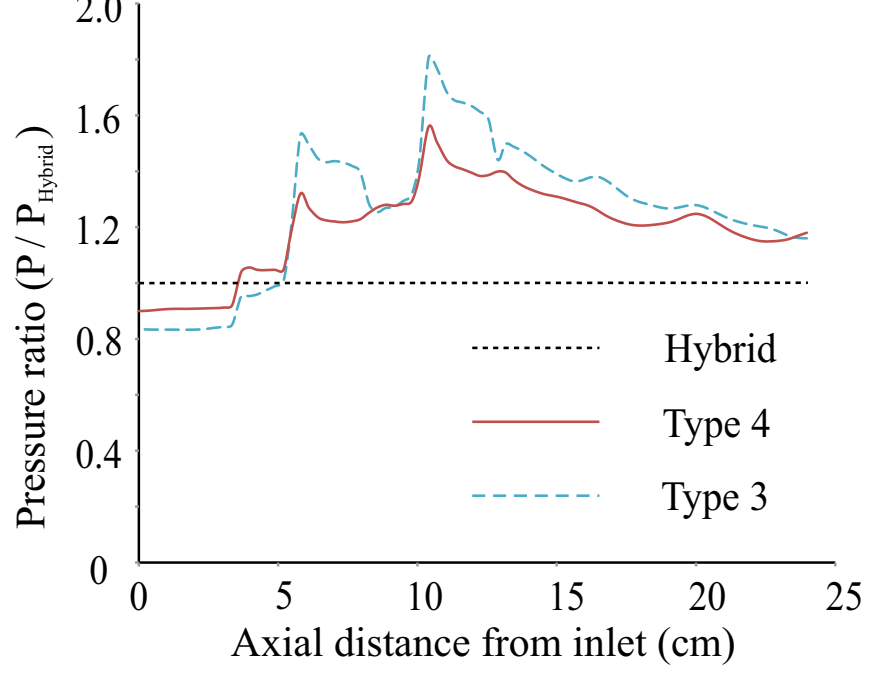


figure 04.pdf

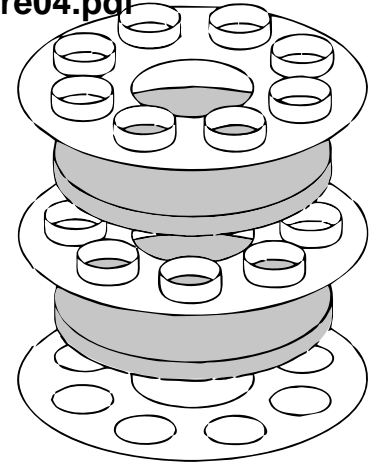

3 Stages

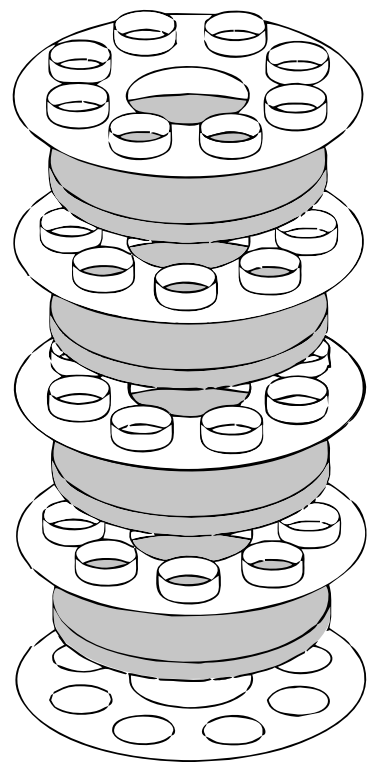

5 Stages

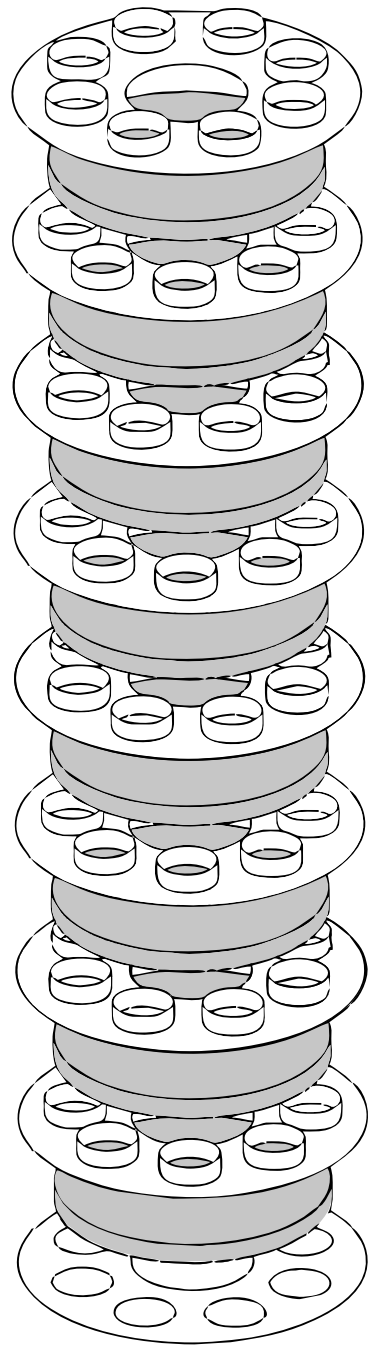

9 Stages 
figure05.pdf

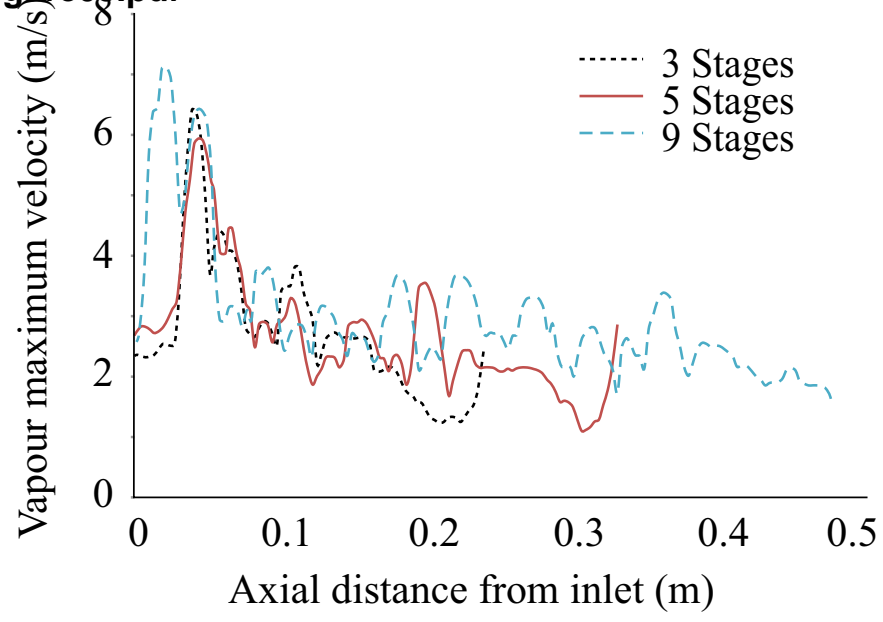




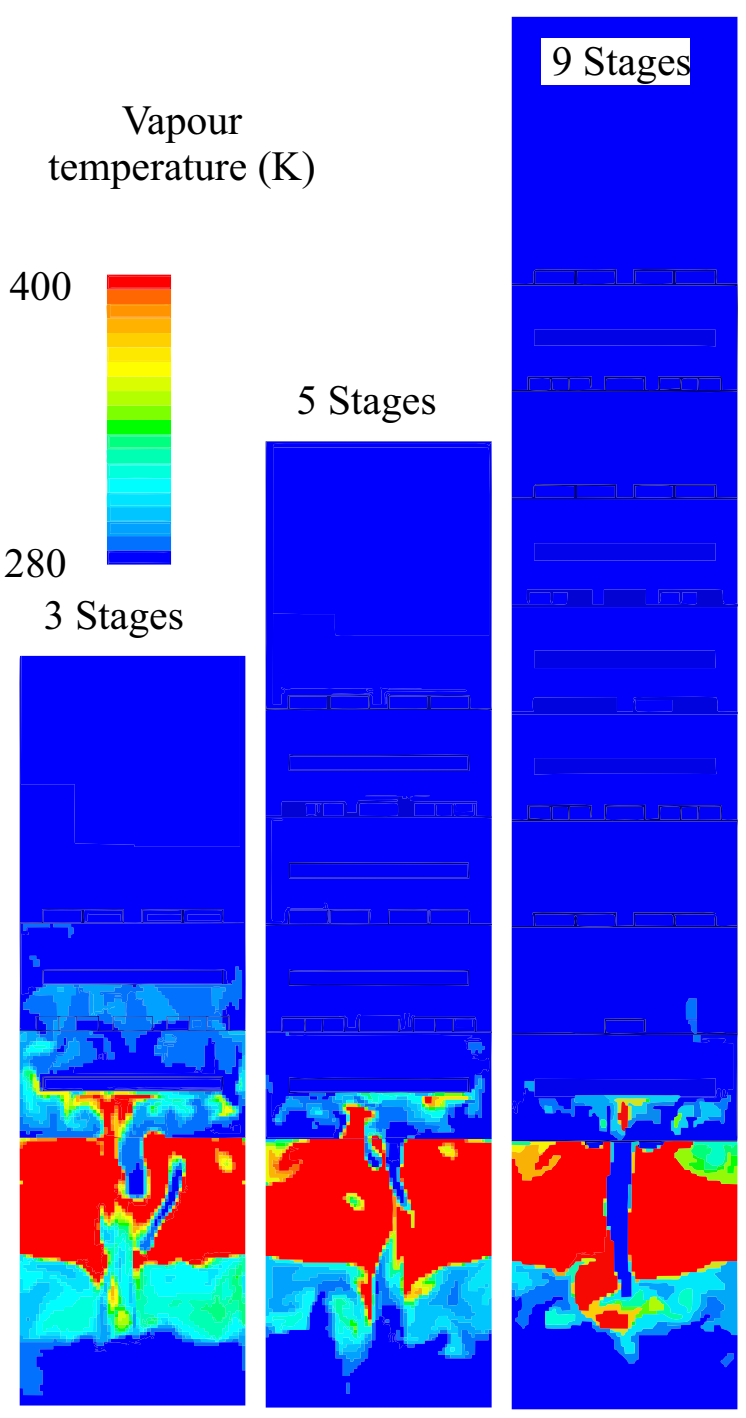

Static gauge

pressure $(\mathrm{Pa})$

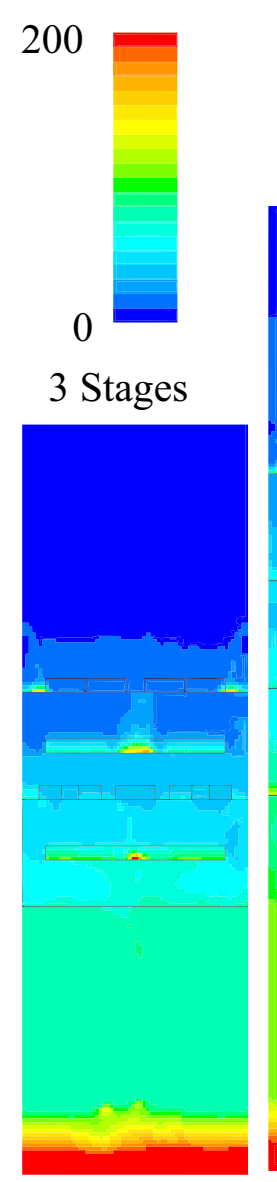

\section{Stages}

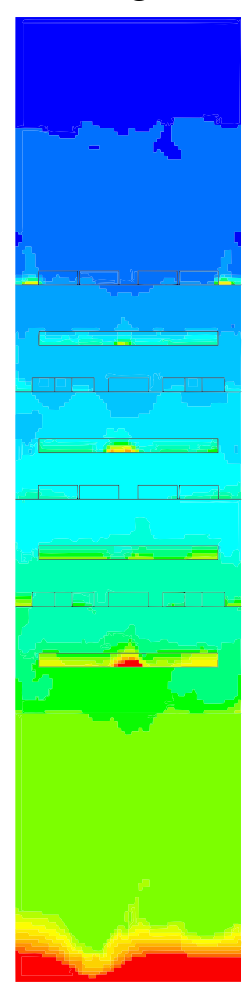

Coolant volume

fraction
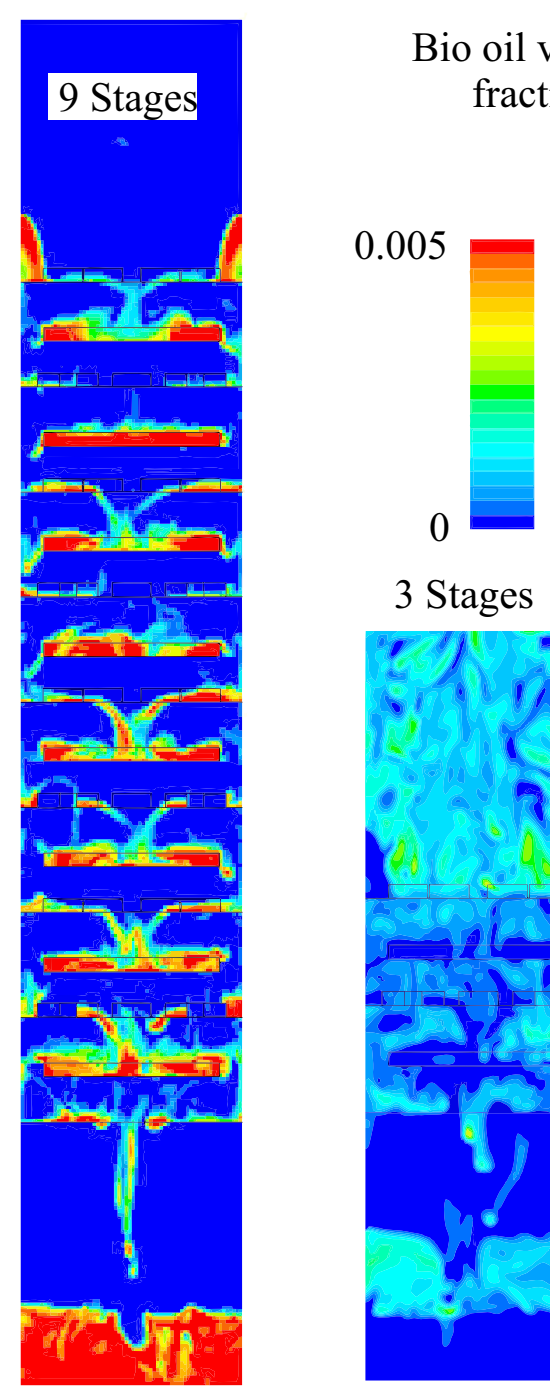

\section{Stages}
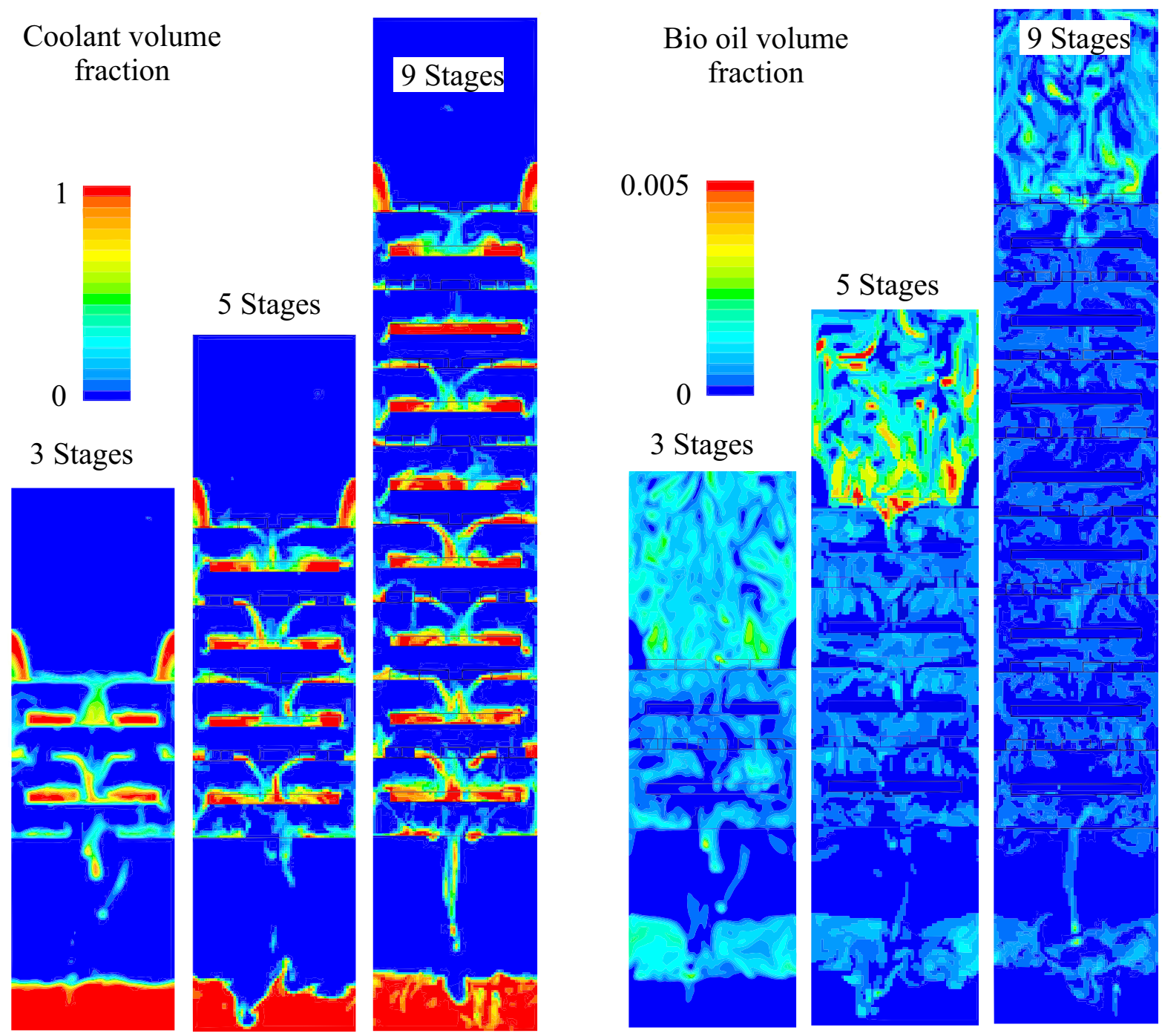
figure0D.pdf

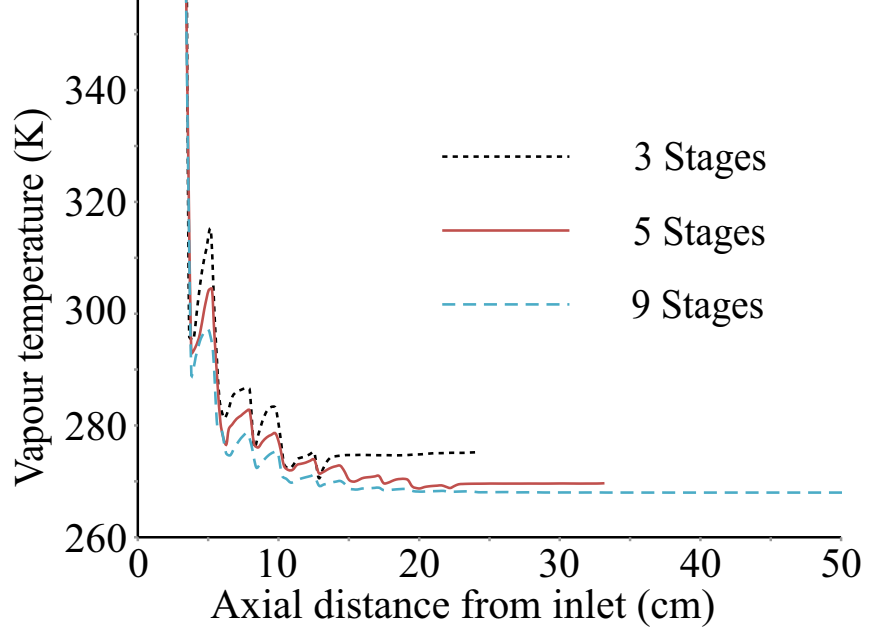


figure08.pdf

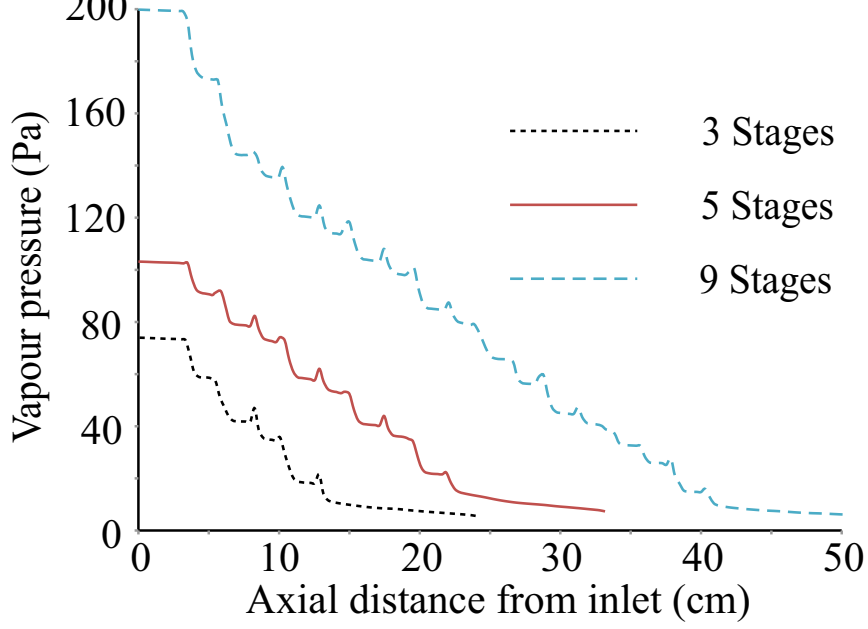



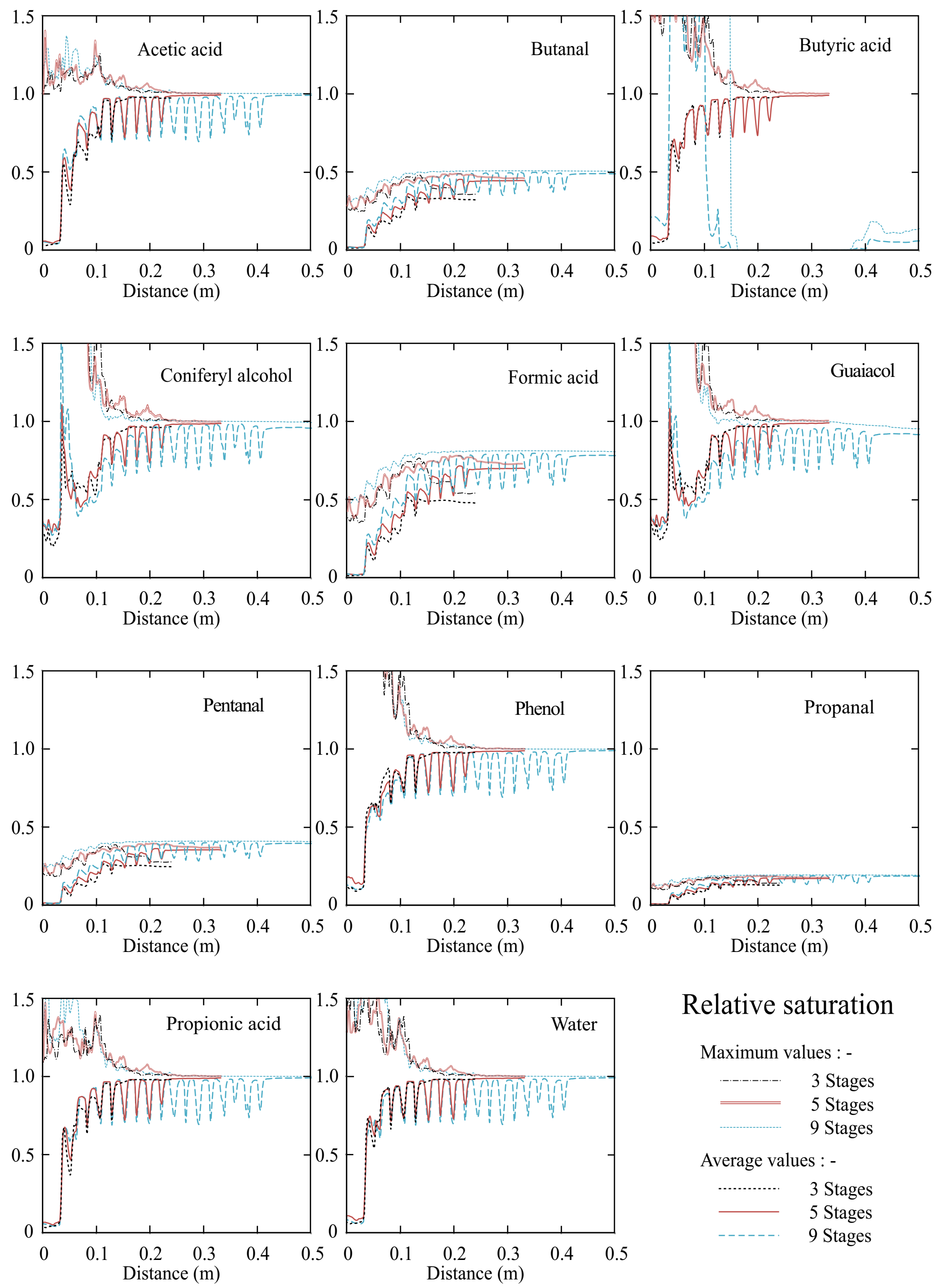

\section{Relative saturation}

Maximum values : -

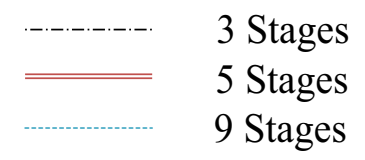

Average values : -

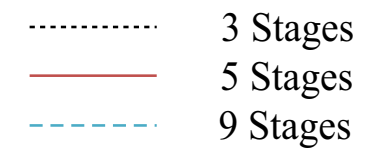



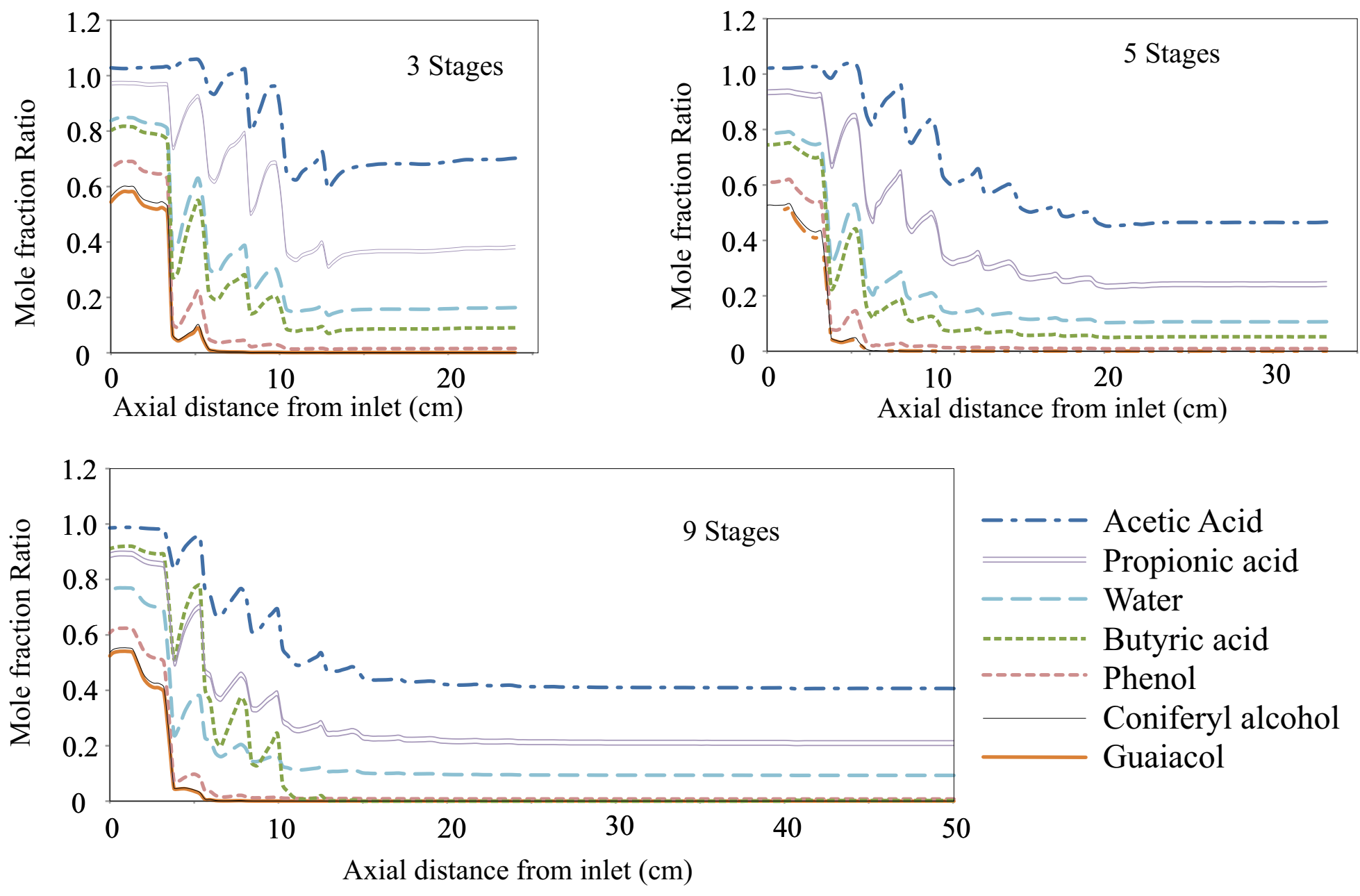

-.-- Acetic Acid $=$ Propionic acid - - - Water Butyric acid Phenol Coniferyl alcohol Guaiacol

Axial distance from inlet $(\mathrm{cm})$ 
Enthalpy - Total
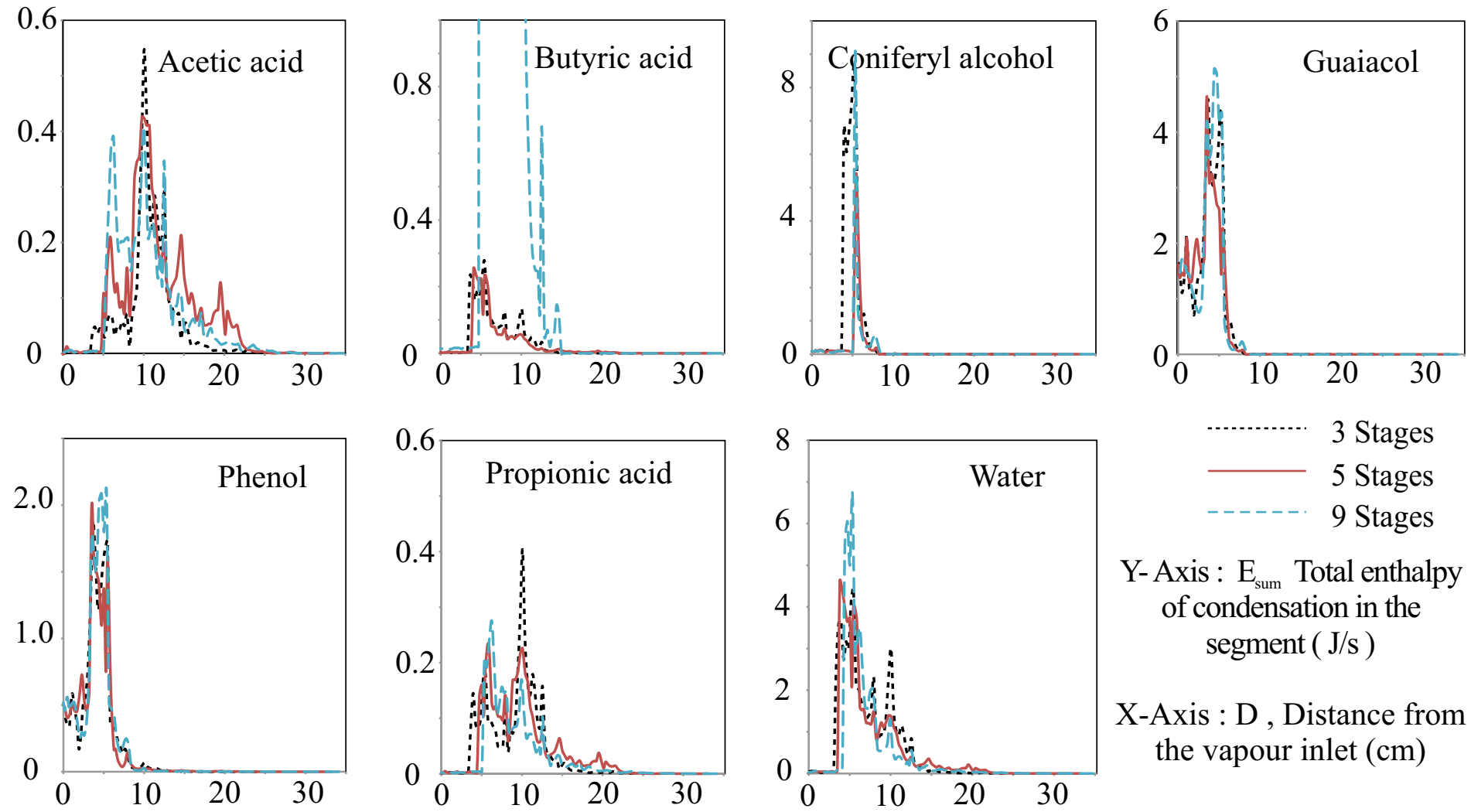

Enthalpy - Maximum
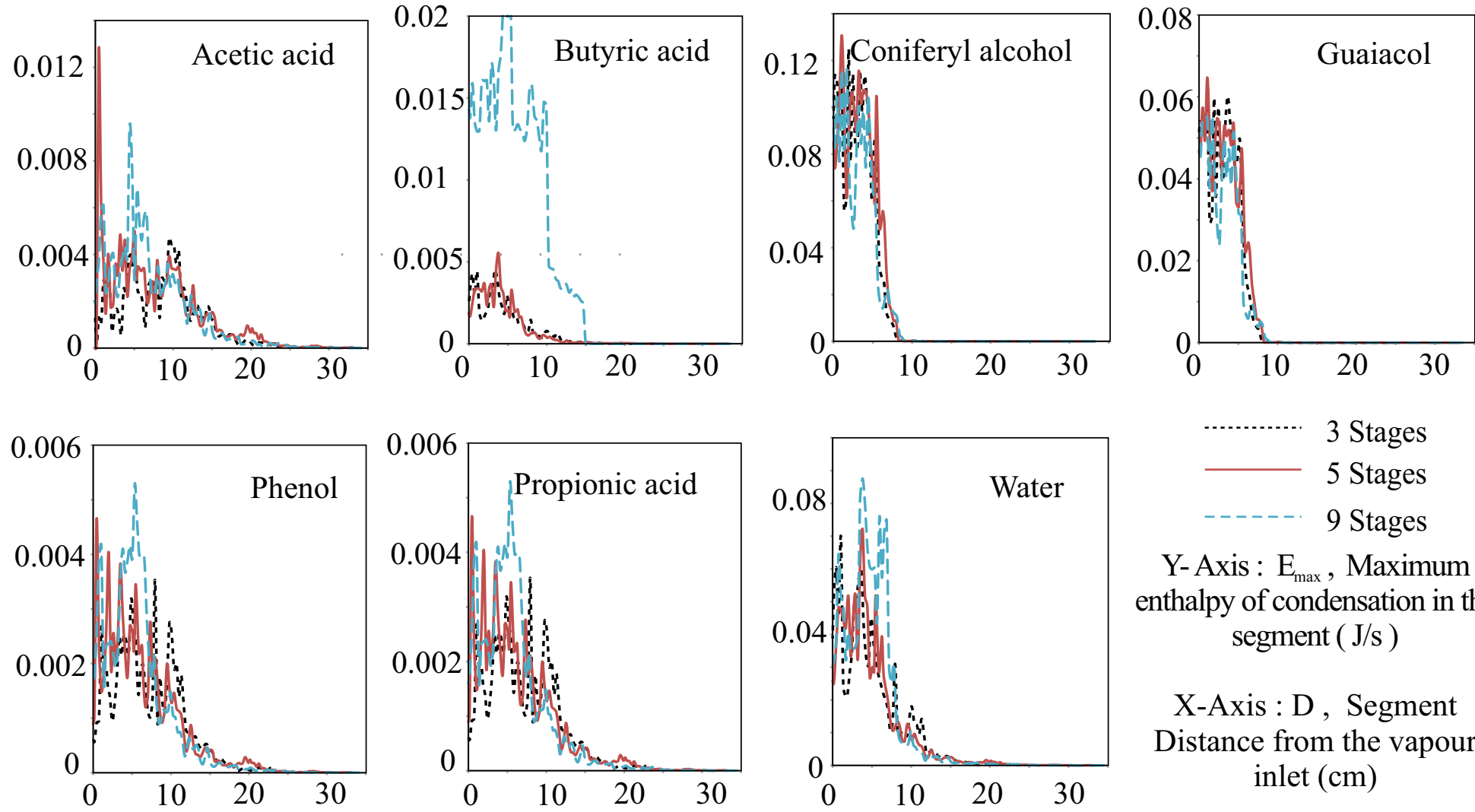

Y-Axis : $E_{\text {sum }}$ Total enthalpy of condensation in the segment $(\mathrm{J} / \mathrm{s}$ )

X-Axis : D, Distance from the vapour inlet $(\mathrm{cm})$

Y-Axis : $\mathrm{E}_{\max }$, Maximum enthalpy of condensation in the segment $(\mathrm{J} / \mathrm{s})$

X-Axis : D, Segment Distance from the vapour inlet $(\mathrm{cm})$ 